\title{
An Analysis of Prospective Teachers' Understanding Levels and Misconceptions in The Subjects of Organic Chemistry: The Case of Alcohols
}

\author{
Gülten ŞENDUR* \& Mustafa TOPRAK \\ Dokuz Eylul University, Izmir, TURKEY
}

Received: 14.08 .2012

Accepted: 07.06.2013

\begin{abstract}
Organic chemistry which is called as chemistry of carbon compounds has an important place in chemistry and other fields of science. The fact that the subject of alcohols in organic chemistry is related to organic compounds such as aldehyde, ketone and carboxylic acid made this subject one of the basic subjects of organic chemistry. For this reason, it was aimed to describe prospective science teachers' understanding levels and misconceptions about alcohols with this study. In this study, alcohol concept test which includes 16 multiple choice items was applied to 77 prospective science teachers to collect data. In addition, semi-structured interview was conducted with 12 prospective science teachers. At the end of study, it was determined that prospective science teachers had difficulties in understanding some topics such as physical properties of alcohols, structural isomerism, oxidation of alcohols and synthesis of alcohols and they had some misconceptions about these topics Key words: alcohols, misconception, organic chemistry, understanding level.
\end{abstract}

DOI No: http://dx.doi.org/10.12973/nefmed162

\section{Summary}

\section{Introduction}

One of the basic problems confronted by students at different levels from secondary education to undergraduate in chemistry education is that concepts are not understand exactly, the relationship between representations of many concepts and cases at macroscopic, submicroscopic and symbolic levels is not established (Çalık, Ayas \& Ünal, 2006; Gabel, Samuel

\footnotetext{
"Corresponding author: Gülten ŞENDUR, Asist. Prof. Dr. in Chemistry Education, Buca Faculty of Education, Dokuz Eylul University, Izmir, TURKEY.

E-mail: gulten.sendur@deu.edu.tr
} 
\& Hunn, 1987; Hinton \& Nakhleh, 1999; Raviola, 2001). Although symbolic and submicroscopic representations are very important in many fields of chemistry, subjects that gain importance are included in organic chemistry.

Organic Chemistry is a subject which studies organic compounds. Considering the content of organic chemistry, it is seen that organic molecules are examined in two groups as hydrocarbons and other functional-group compounds mostly. Within these compounds, alcohols are a fundamental topic in Organic Chemistry since it plays a part in the synthesis and reactions of aldehyde, ketone, carboxylic acid and alkenes. In this sense, understanding molecular structure of alcohols, basic reactions at the sub-microscopic and symbolic level can be the basis for other organic molecules. Therefore, studies on determining the level of understanding of students at different education levels about alcohols are very important. However, when analyzing the relevant literature, it was found out that such types of studies were extremely limited. In these limited number of studies, certain aspects of alcohols such as isomerism, solubility, classification of alcohols, acidity characteristic were examined (Potgietera \& Davidowitz, 2011; Schmidt, 1992; Hassan, Hill \& Reid, 2004; Chiu, 2007; Karaer, 2007).

For all of these reasons, it was aimed to determine levels of understanding of prospective science teachers relating to all aspects of alcohols and misconceptions by use of different instruments (conception test and interview) in this study. For this purpose, following questions were tried to be answered in this study:

1. What are the levels of understanding of prospective science teachers regarding alcohols?

2. What are the prospective science teachers' misconceptions about alcohols? Are there any misconceptions in common with those identified in the literature and different from the literature?

\section{Method}

Since qualitative and quantitative data collection tools were used together and also levels of understanding of prospective teachers were analyzed deeply, case study method was preferred (Çepni, 2007; Yin, 1984). In this study, single-case (holistic) design was used.

\section{Sample}

Sample of the study consists of 77 prospective science teachers from Dokuz Eylul University, Buca Faculty of Education department of science teacher in 2010-2011 academic year. 


\section{Data collection tools}

In this study, alcohol concept test and semi-structured interviews were used as data collection tools. Alcohol concept test comprising of 16 multiple choice questions was developed by the researchers to investigate prospective teachers' understanding levels and misconceptions. Each question in the test was prepared to comprise of five choices considering categories of "sound understanding, partial understanding with specific misconception, specific misconception" used in various studies in the literature (Abraham, Grzybowski, Renner \& Marek, 1992; Azizoğlu, Alkan \& Geban, 2006; Çalık, 2005; Ünal, Cosstu \& Ayas, 2010). In the end of pilot study, the reliability coefficient of the test (Cronbach Alpha) was calculated as 0,74 . Semi-structured interviews were conducted to obtain more detailed information about levels of understanding of prospective teachers about basic concept and reactions of alcohols. Total 12 students were chosen for the interviews.

Analysis of Data

The analysis of test items and interview questions were evaluated by five categories as "sound understanding, partial understanding, partial understanding with specific misconception, specific misconception, no response/no understanding". At the last stage, these data were presented in percentage and frequency.

\section{Results and discussion}

The findings of this research indicate that sound understanding levels of prospective science teachers was not sufficient under the titles of "structure of alcohols, the basic properties of alcohols, solubility of alcohols, structural isomerism, nomenclatures of alcohols, oxidation of alcohols, reactions with sodium, reactions with Lucas reagent, dehydration reactions, synthesis of alcohols" and the misconceptions about these topics was high as $48 \%$. While some of these misconceptions are parallel to the ones in the literature, some are identified for the first time in this research. For example, some misconceptions such as "the cyclic molecules are not characteristic of alcohol", "to call a molecule as alcohol, this molecule should not include $\pi$ bond" were originally found in this research. On the other hand, the misconception "to call a molecule as alcohol, it is enough that hydroxyl group ($\mathrm{OH}$ ) is attached to a carbon atom in the molecule" is parallel to the findings of Potgietera and Davidowitz (2011).

From the findings, it was determined that prospective science teachers also hold misconceptions about solubility of alcohols. The misconceptions determined relating to 
solubility of alcohols that "when the hydrocarbon chain becomes longer, the alcohol becomes more soluble in water, when the degree of branching in the chain increases, the alcohol becomes less soluble in water, branched-chain and straight-chain alcohols which they have the same number of carbon atoms has the same solubility in water". Prospective science teachers have problems about the basic properties of alcohols and structure isomerism. For example, "the general formula of all monohydric alcohol is $\mathrm{C}_{\mathrm{n}} \mathrm{H}_{2 \mathrm{n}} \mathrm{O}$ ", "only trihydric alcohols are structural isomers with ethers." misconceptions were identified for the first time in this research. In addition, it was found out in the study that many prospective teachers were not of the sufficient levels for symbolic representations of chemical reactions of alcohols and they could not understand the functional-group compounds such as aldehyde, ketone. 


\title{
Öğretmen Adaylarının Organik Kimya Konularındaki Anlama Düzeylerinin ve Kavram Yanılgılarının Bir Analizi: Alkoller Örneği
}

\section{Gülten ŞENDUR ${ }^{\dagger}$ \& Mustafa TOPRAK}

\author{
Dokuz Eylül Üniversitesi, İzmir, TÜRKİYE
}

Makale Gönderme Tarihi: 14.08.2012

Makale Kabul Tarihi: 07.06.2013

Özet - Karbon bileşikleri kimyası olarak adlandırılan organik kimya, içeriği ile gerek kimyanın gerekse fen bilimlerinin diğer alanları için önemli bir yere sahiptir. Organik kimyanın içeriğinde yer alan alkoller konusunun aldehitler, ketonlar ve karboksili asitler gibi organik bileşiklerle ilişkili olması, bu konuyu organik kimyanın temel konularından biri haline getirmiştir. Bu nedenle, bu çalışma ile fen bilgisi öğretmen adaylarının alkoller konusuna ilişkin anlama düzeylerinin ve mevcut kavram yanılgılarının ortaya çıkarılması amaçlanmıştır. Araştırmada veri toplama amaciyla, 16 çoktan seçmeli sorudan oluşan alkoller konusu kavram testi, 77 fen bilgisi öğretmen adayına uygulanmıştır. Ayrıca, kavram testi sonuçlarına göre seçilen 12 öğretmen adayı ile de yarı yapılandırılmış görüşme yapılmıştır. Araştırma sonucunda, öğretmen adaylarının alkollerin fiziksel özellikleri, yapısal izomeri, alkollerin yükseltgenmeleri ve eldeleri konularında anlama düzeylerinin düşük düzeyde olduğu ve bazı kavram yanılgılarına sahip olduğu belirlenmiştir.

Anahtar kelimeler: alkoller, kavram yanılgısı, organik kimya, anlama düzeyi

\section{Giriş}

Kimya eğitiminde, ortaöğretimden lisans düzeyine kadar faklı seviyelerdeki öğrencilerde karşılaşılan temel problemlerden biri kavramların tam olarak kavranamaması, pek çok kavram ve olayın makroskobik, mikroskobik ve sembolik düzeydeki temsilleri arasındaki ilişkinin kurulamamasıdır. Nitekim yapılan araştırmalar, öğrencilerin mikroskobik ve sembolik gösterimleri anlamada zorlandıklarını ortaya çıkarmıştır (Çalık, Ayas \& Ünal, 2006; Gabel, Samuel \& Hunn, 1987; Hinton \& Nakhleh, 1999; Raviola, 2001). Kimyanın pek çok alanında sembolik ve mikroskobik gösterimler önemli bir yer tutmakla beraber, bunların

\footnotetext{
†iletişim: Gülten ŞENDUR, Yrd. Doç. Dr., Kimya Eğitimi Anabilim Dalı, Buca Eğitim Fakültesi, Dokuz Eylül Üniversitesi, İzmir, TÜRKIYE
} 
en çok ağırlık kazandığı konular organik kimya içersinde yer almaktadır.

Organik kimya, karbon bileşikleri kimyası olarak ayrı bir kimya alanı olarak ele alınmaktadır. Karbon bileşikleri canlıların ana maddeleri olan, proteinler, karbonhidratlar, nükleik asitler (DNA, RNA) gibi pek çok molekülün yapısını oluşturduğu gibi plastiklerden, ilaçlara ve parfümlere kadar oldukça geniş bir alanda günlük hayatımızın bir parçası haline gelmiştir (Solomons \& Craig, 2001). Bunun sonucunda organik kimyanın önemi artmıştır. Organik kimyanın anlaşılmasında, molekül yapılarının tam olarak doğru bir şekilde kavranması son derece önemlidir. Nitekim, bileşiklerin fiziksel ve kimyasal özellikleri moleküldeki atomların bağlanma düzenine göre farklılık gösterdiğinden, organik moleküllerin yapıları organik kimyanın temelini oluşturmaktadır. Organik kimya içeriğine bakıldığında, organik moleküllerin çoğunlukla, hidrokarbonlar ve diğer fonksiyonel gruplu bileşikler üzere iki grupta incelendiği görülmektedir. Bunlar içerisinde yer alan alkoller, aldehit, keton, karboksilli asit ve alkenlerin sentez ve reaksiyonlarında yer almasından dolayı, organik kimyanın önemli konularından biri haline gelmiştir. Bu bağlamda, özellikle alkollerin moleküler yapısının, temel reaksiyonlarının mikroskobik ve sembolik düzeyde kavranması diğer organik moleküller için de temel oluşturabilir. Bundan dolayı farklı öğrenim seviyelerindeki öğrencilerin alkoller konusuna ilişkin anlama düzeylerini belirlemeye yönelik çalışmalar son derece önemlidir. Ancak, ilgili literatür incelendiğinde, bu tarz çalışmaların son derece sınırlı olduğu saptanmıştır.

Yapılan çalışmalardan birinde Karaer (2007), Kimya IV dersini alan fen bilgisi öğretmen adaylarına, alkollerin sudaki çözünürlüğünü kavratmak amacıyla dramatizasyon yöntemini uygulamıştır. Çalışmada TGA yönteminin uygulanması sırasında, öğrencilere alkol örnekleri verilerek (etil alkol, izopropil alkol ve n-bütil alkol) bunların sudaki çözünürlüklerini tahmin etmeleri istenmiş ve öğrencilerin \%86'l1k kısmının alkollerin tamamın suda çözündüğüne inandıkları ortaya çıkmıştır.

Chiu (2007), tarafından yürütülen bir araştırmada ise Tayvan'da farklı yaş gruplarındaki lise öğrencilerinin sahip oldukları kimya kavramlarının ortaya çıkartılması amaçlamıştır. Çalışmanın sonuçları, alt ve üst düzeydeki öğrencilerin organik bileşikler ile ilgili benzer kavram yanılgılarına sahip olduğunu göstermiştir. Örneğin, üst sınıflardaki öğrencilerin \%29'u etil alkolün, içerdiği -OH grubundan dolayı bazik olduğunu ifade ederken, bu oran alt düzeydeki sınıflarda \%27 olmuştur. Diğer bir ortak yanılgı da ise, etil alkol molekülünün çok sayıda hidrojen içerdiği için asidik özellik taşıdığını ifade edenler üst gruplarda \%10 iken, alt 
gruplarda \%26 olmuştur. Benzer bulgular Ross ve Munby’nin (1991) bulguları ile de uyuşmaktadır. Bir diğer ilginç bulgu ise, üst gruplarda yer alan öğrencilerin \%29'u bütün organik moleküllerin nötr olduğu için etil alkolün de nötr özellik göstereceğini ifade etmesidir.

Bir diğer çalışmada ise Schmidt (1992), 11-13. sınıflarda öğrenim gören 7,441 öğrenciye alkol ve eterlerde izomeri konusunu temel alan bir test uygulamıştır. Çalışma sonucunda öğrencilerin, izomerlerin sadece aynı sınıf bileşiklerde ve dallanmış karbon zincirlerinde görülebileceğine inandıkları orta çıkmıştır. Örneğin bu çalışmada, etil alkol ve dimetil eter aynı sınıfta yer almadığı için birbirinin yapı izomeri olmayacağı ifade edilmiştir. Schmidt araştırma sonuçlarını, öğrencilerin izomerinin tanımı ve uygulamaları ile ilgili kavramlarının yetersiz olmasına, izomeri kelimesinin önündeki -izo hecesinden dolayı öğrencilerin izomeriyi sadece dallanmış karbon zincirinde olabileceği biçiminde yorumlamasına bağlamıştır.

Hassan, Hill ve Reid (2004) tarafından yürütülen bir diğer araştırmada ise, İskoçya'daki üniversitelerde kimya bölümüne başlayan birinci sınıf öğrencilerin organik kimya dersini almadan önce, liseden edindikleri organik kimya bilgilerinin ortaya çıkartılması hedeflemiştir. $\mathrm{Bu}$ amaçla, kimya bölümünde okuyan 367 üniversite birinci sınıf öğrencisine fonksiyonel gruplar, kovalent bağ, bağ polarlığı, streokimya ve molekül geometrisi konularını içeren yapılandırılmış grid uygulanmıştır. Öğrencilerin \%33'ü etil metil eterin yapı izomerlerini (npropil alkol ve 2-propanol) doğru bir şekilde seçerken, \%14 ise izomerlerden sadece birini seçmişlerdir. Geriye kalan \%30’luk kısım ise, etil metil eterin farklı bir gösterimi olan molekülü yapı izomerisi olarak almıştır. Gridte yer alan bir başka soruda ise öğrencilerden verilen moleküller arasında sekonder alkolleri seçmeleri istenmiştir. Öğrencilerin \%61'lik kısmı doğru molekülü (2-propanol) seçerken, \%11'i ise bir tersiyer alkol olan 2-metil-2propanol'ü sekonder alkol olarak seçmişlerdir.

Başka bir araştırma ise Potgietera ve Davidowitz (2011) tarafından yürütülmüştür. Bu çalışmada, araştırmacılar Güney Afrika'da seçtikleri 3 üniversitedeki birinci sınıf öğrencilerinin kimyadaki yeterliliklerini belirlemek üzere 65 sorudan oluşan bir test geliştirmişlerdir. Geliştirilen test toplam 1847 birinci sınıf kimya öğrencisine uygulanmıştır. Testte, organik kimya ile ilgili üç soru yöneltilmiştir. Araştırma sonucunda, pek çok öğrencinin karboksilli asitler de dahil olmak üzere hidroksil grubu taşıyan bütün moleküllerin, alkol olduğuna inandıkları ortaya çıkmıştır. Aynı zamanda öğrencilerin \%68'lik kısmı verilen moleküller içerisinde iki alkol molekülünü tanıyamamıştır. 
Yukarıdaki çalışmalardan da anlaşılacağı üzere, farklı öğrenim seviyelerindeki öğrencilerin alkollere ilişkin anlama düzeyleri ve kavram yanılgılarını belirlemeye yönelik sınırlı sayıda çalışma mevcut olup bu çalışmalarda da alkollerin sadece belirli yönleri (izomeri, çözünürlük, alkollerin tanımlanması, sınıflandırılması, asitlik özelliği) ele alınmıştır. Aynı zamanda bu araştırmalarda, öğrencilerin kavram yanılgılarını ortaya koymak ve onları ayrıntılarıyla açıklamak amacıyla farklı ölçme araçları bir arada kullanılmamıştır. Literatürdeki bu eksikliklerden yola çıkarak bu çalışma planlanmıştır. Alkoller konusunun çalışmada seçilmesinin nedeni, alkollerin diğer organik moleküllerin anlaşılması için temel oluşturması ve ilköğretim fen ve teknoloji müfredatı içersindeki maddenin halleri ve 1sı (8. Sınıf) ünitesi içersinde alkolleri de kapsayan etkinliklere yer verilmesidir. Bu bağlamda, kimya kavramlarını öğrencilere sunmada önemli role sahip fen bilgisi öğretmen adaylarının bu kavramlarla ilgili anlama düzeyleri ve kavram yanılgıları saptanmaya yönelik çalışmalar da önem kazanmaktadır. Bu nedenle, çalışmamızın alkoller konusunu öğretecek öğretmenlere ve bu konuda araştırma yapmayı düşünen kimya ve fen eğitimcilerine 1şık tutması açısından önemli olduğu düşünülmektedir.

Tüm bu sebeplerden dolayı, bu çalışmada, fen bilgisi öğretmen adaylarının alkollerin tüm yönlerine ilişkin anlama düzeyleri ve kavram yanılgıları farklı ölçme araçları (kavram testi ve görüşme) kullanılarak tespit edilmesi amaçlanmıştır. $\mathrm{Bu}$ amaç doğrultusunda, araştırmada aşağıdaki sorulara cevap aranmıştır:

1. Fen bilgisi öğretmen adaylarının alkoller konusuna ilişsin anlama düzeyleri ne seviyededir?

2. Fen bilgisi öğretmen adaylarında, alkoller ile ilgili var olan kavram yanılgıları nelerdir? Bu kavram yanılgılarından literatürle ortak olanlar ve literatürden farklı olanlar var midır?

\section{Yöntem}

\section{Araştırma Modeli}

Araştırmada, nitel ve nicel veri toplama araçlarının bir arada kullanılması ve aynı zamanda öğretmen adaylarının anlama düzeylerinin derinlemesine bir şekilde incelenmesi nedeni ile örnek olay yöntemi tercih edilmiştir. Araştırmada, örnek olay çalışma desenlerinden bütüncül tek durum deseni kullanılmıştır. Bütüncül tek durum desenlerinde, bir kurum, bir program, bir okul gibi tek bir analiz birimi incelenmektedir (Çepni, 2007; Y1ldırım \& Şimşek, 2011; Yin, 1984) Bu araştırmada da, tek bir analiz birimi olarak fen bilgisi 
öğretmenliği 2. sınıfta öğrenim gören öğretmen adayları alındığından bütüncül tek durum deseninin kullanılması uygun bulunmuştur.

\section{Çalışma Grubu}

Araştırmanın çalışma grubunu 2010-2011 eğitim-öğretim yılı bahar döneminde Dokuz Eylül Üniversitesi, Buca Eğitim Fakültesi Fen Bilgisi Öğretmenliği programı ikinci sınıfında öğrenim gören 47'si kız, 30’u erkek 77 öğretmen adayı oluşturmaktadır. Çalışma grubundaki öğretmen adayları 20-22 yaş aralığındadır. Örneklemdeki bu öğretmen adayları alkoller konusunu “Kimya IV (Organik Kimya)" dersi kapsamında 2010-2011 eğitim-öğretim yılının bahar döneminde görmüşlerdir. Aynı zamanda ortaöğretim 12. Sınıf kimya ders programında alkoller konusunun yer alması ve üniversiteye giriş sınavlarında da bu konudan soru sorulması nedeniyle öğretmen adaylarının alkoller konusuna ilişkin ön bilgileri de mevcuttur. $\mathrm{Bu}$ nedenlerden dolayı öğretmen adaylarının sahip oldukları bilgilerin, kavram testi ve yarıyapılandırılmış görüşmede yöneltilecek sorulara cevaplayacak nitelikte olduğu düşünülmüştür. Araştırmanın çalışma grubu, amaçlı örnekleme yöntemlerinden tipik durum örnekleme yöntemi kullanılarak oluşturulmuştur. Araştırmada, tipik durum örneklemesinin benimsenmesinin nedeni fen bilgisi öğretmen adaylarının alkoller konusuna ilişkin anlama düzeyleri ve kavram yanılgıları hakkında bilgi sahibi olmak ve bu konuya ilişkin bilgi sahibi olmayanları bilgilendirmektedir (Patton, 1987; Yıldırım \& Şimşek, 2011).

\section{Veri Toplama Araçları}

Araştırmada, alkoller konusu kavram testi alkoller konusu kavram testi ve yarı yapılandırılmış görüşme olmak üzere iki ayrı veri toplama aracı kullanılmıştır.

\section{Alkoller Konusu Kavram Testi}

16 çoktan seçmeli sorudan oluşan kavram testi, araştırmacılar tarafindan öğretmen adaylarının anlama düzeyleri ve kavram yanılgılarını saptamak amacıyla geliştirilmiştir. Kavram testi Kimya IV dersi kapsamında "Alkoller" konusu işlendikten bir hafta sonra araştırmacılar tarafından bizzat öğretmen adaylarına, bir ders saati süresince uygulanmıştır. Kavram testinde yer alan sorular, fen bilgisi öğretmenliği Kimya IV(organik kimya) ders içeriğine göre hazırlanmış olup, üniversite düzeyindeki çeşitli organik kimya ders kitaplarından yararlanılmıştır. Ayrıca, örneklem dışından organik kimya ders başarı puanlarına göre seçilen 12 öğretmen adayı ile yarı-yapılandırılmış görüşme yapılmıştır. Görüşmeden elde edilen veriler, literatürde saptanan kavram yanılgıları (Hassan, Hill \& Reid, 2004; Potgietera \& Davidowitz, 2011; Schmidt, 1992) ve araştırmacıların kendi deneyimleri 
de dikkate alınarak test hazırlanmıştır. Testteki her bir soru, beş seçenek içerecek şekilde literatürde çeşitli çalışmalarda da kullanılan "tam anlama, spesifik kavram yanılgılı kısmen anlama, spesifik kavram yanılgısı" kategorileri dikkate alınarak hazırlanmıştır (Abraham, Grzybowski, Renner \& Marek,1992; Azizoğlu, Alkan \& Geban, 2006; Çalık, 2005; Ünal, Coştu \& Ayas, 2010, ). Anlama seviyesi ile ilgili olan bu kategoriler ve içerikleri şöyledir:

- Tam Anlama (TA): Bilimsel olarak doğru cevap ve açıklamaları içerir.

- Spesifik Kavram Yanılgılı Kısmen Anlama (SKYKA): Bilimsel olarak doğru cevap ve doğru olmayan açıklamaları içerir.

- Spesifik Kavram Yanılgısı (SKY): Bilimsel olarak doğru olmayan cevap ve açıklamaları içerir.

2.Soru
Yukarıda verilen moleküllerden hangileri $\mathrm{C}_{\mathrm{n}} \mathrm{H}_{2 \mathrm{n}+2} \mathrm{O}$ kapalı formülüne sahiptir?
A) I, II ve III nolu bileşikler bu kapalı formüle uyar çünkü tüm mono alkoller $\mathrm{C}_{\mathrm{n}} \mathrm{H}_{2 \mathrm{n}+2} \mathrm{O}$ kapalı
formülü ile gösterilir.
B) IV ve $\mathrm{V}$ nolu bileşikler bu kapalı formüle uyar çünkü sadece eterler $\mathrm{C}_{\mathrm{n}} \mathrm{H}_{2 \mathrm{n}+2} \mathrm{O}$ kapalı formülü
ile gösterilir.
C) III ve IV nolu bileşikler bu kapalı formüle uyar çünkü sadece halkalı yapılı mono alkoller ile
eterler $\mathrm{C}_{\mathrm{n}} \mathrm{H}_{2 \mathrm{n}+2} \mathrm{O}$ kapalı formülü ile gösterilir.
D)* I ve $\mathrm{V}$ nolu bileşikler bu kapalı formüle uyar çünkü sadece düz zincirli ve $\pi$ bağı içermeyen
mono alkoller ile eterler $\mathrm{C}_{\mathrm{n}} \mathrm{H}_{2 \mathrm{n}+2} \mathrm{O}$ kapalı formülü ile gösterilir.
E) I ve $\mathrm{V}$ nolu bileşikler bu kapalı formüle uyar çünkü sadece $2 \mathrm{C}$ ' lu mono alkoller ile eterler
$\mathrm{C}_{\mathrm{n}} \mathrm{H}_{2 \mathrm{n}+2} \mathrm{O}$ kapalı formülü ile gösterilir.
* Doğru Seçenek (Tam Anlama Kategorisi)

Şekil 1 Kavram Testindeki Örnek Bir Soru

Testteki her sorunun 4 çeldiricisi bulunup, bunların 3 tanesi spesifik kavram yanılgısı, 1 tanesi de spesifik kavram yanılgılı kısmen anlama kategorisine göre hazırlanmıştır. Çeldiriciler hazırlanırken buna başvurulmasının nedeni, öğretmen adaylarında çıkabilecek olası tüm kavram yanılgılarını ortaya çıkarmaktır. Testin kapsam geçerliği için iki kimya eğitimi uzmanı ile organik kimya alanında uzman iki öğretim üyesinin görüşleri alınmış ve bu kişilerin önerilerine göre pilot çalışma yapılmak üzere teste son şekli verilmiştir. Pilot çalışma, çalışma grubu dışında kalan organik kimya dersini alan 48 öğretmen adayı ile 
yürütülmüştür. Literatürdeki çeşitli araştırmalar da, pilot çalışmadaki öğrenci sayısının kabul edilebilir düzeyde olduğunu desteklemektedir (Coştu, Ayas \& Niaz, 2009, Özmen, 2007). Kavram testinde, doğru seçeneğe 1, yanlış ve boş bırakılan seçeneklere de sıfır puan verilmiştir. Maddelerin doğru ve yanlış olarak iki seçenekli olarak kodlandığında durumlarda Cronbach alfa katsayısı ile Kuder-Richardson-20 (KR-20) katsayısı eşittir (Ebel \& Frisbie, 1991, Suen, 1990, Sax 1997). Pilot çalışma sonunda, testin güvenirlik katsayısı (Cronbach Alfa) 0,74 olarak hesaplanmıştır. Cronbach alfa katsayısının 0,70'den büyük olması bir testin güvenilir olarak kabul edildiğini göstermektedir (Büyüköztürk, Çakmak, Akgün, Karadeniz \& Demirel, 2008; Özdamar, 2004). Pilot çalışmandan 4 hafta sonra, gerçek örnekleme alkoller konusunun işlenmesinin ardından kavram testi uygulanmıştır. $\mathrm{Bu}$ uygulama sonucunda Cronbach Alpha iç tutarlılık katsayısının 0,93 olduğu tespit edilmiştir. Bu sonuçlara göre, testten elde edilen verilerin güvenirlik düzeyinin oldukça yeterli olduğu söylenebilir. Kavram testindeki soruların içeriği Tablo 1'de gösterilmiştir.

Tablo 1 Kavram Testinde Yer Alan Soruların Konu Alanları

\begin{tabular}{lc}
\hline \multicolumn{1}{c}{ Konu Alanı } & Soru Numarası \\
\hline Alkollerin fiziksel özellikleri (Kaynama Noktası) & 1 \\
Alkollerin genel özelliği & 2 \\
Alkol olma koşulları & 3 \\
Alkollerin fiziksel özellikleri (Sudaki çözünürlük) & 4,5 \\
Alkollerde yapisal izomeri & 6 \\
Alkol çeşitleri & 7 \\
Alkollerin adlandırılması & 8 \\
Alkollerin tepkimeleri (Sodyumla tepkimeleri) & 9 \\
Alkollerin tepkimeleri (Lucas ayıracı) & 10 \\
Alkollerin tepkimeleri (Yükseltgenme) & 11,13 \\
Alkollerin tepkimeleri (Dehidrasyon) & 12 \\
Alkollerin eldesi (Alkil halojenürlerden eldesi) & 14 \\
Alkollerin eldesi (Ketonlardan eldesi) & 15 \\
Alkollerin eldesi (Karboksilli asitlerden eldesi) & 16 \\
\hline
\end{tabular}

\section{Yart-Yapılandırılmış Görüşme}

Öğretmen adaylarının, alkol konusunun temel kavram ve reaksiyonlarına ilişkin anlama düzeyleri ve kavram yanılgıları hakkında daha detaylı bilgi edinmek amacıyla yarı yapılandırılmış görüşmeler yürütülmüştür. Görüşmelere, alkol kavram testinde aldıkları puanlara göre yüksek, orta ve düşük grupta yer alan toplam 12 öğrenci seçilmiştir. Görüşmeler, her bir öğretmen adayı ile bireysel yapılmış ve 20-25 dakikalık bir sürede tamamlanmıştır. Görüşmelerde ses kaydedici kullanılmış ve tüm görüşme süreci kaydedilmiştir. Görüşmede öğretmen adaylarına, araştırmacılar tarafından geliştirilen dört soru yöneltilmiştir. Ayrıca, öğrencilere yöneltilen bu ana sorular dışında, verdikleri cevaplarla 
ilgili bazı alt sorular da yöneltilmiştir. Görüşme sorularının geliştirilmesi sürecinde kimya eğitimi ve organik kimyada uzman üç kişinin görüşü alınmıştır. Uzmanların önerileri doğrultusunda gerekli düzeltmeler ve eklemeler yapıldıktan sonra görüşme sorularına son hali verilmiştir. Bu sorular ve içeriği Tablo 2'de sunulmuştur.

Tablo 2 Görüşme Sorularının İçeriği

\begin{tabular}{lll}
\hline \multicolumn{2}{l}{ Soru } & İçeriği \\
\hline 1. & Soru & Alkollerin tanımlanması \\
2. & Soru & Alkollerin fiziksel özellikleri \\
3. & Soru & Alkol ve eterlerin birbirinden ayırt edilmesi \\
4. & Soru & Alkollerin tepkimeleri \\
\hline
\end{tabular}

Görüşmeler süresince, öğretmen adaylarından sorularda adı geçen reaksiyonları ve moleküllerin açık formüllerini de yazmaları istenmiştir. Böylelikle, öğretmen adaylarının sembolik düzeydeki gösterimlerinin de ortaya çıkarılması amaçlanmıştır. Görüşmelerin daha verimli bir şekilde yürütülebilmesini sağlamak ve görüşme sürecinde dikkat edilmesi gereken önemli noktaları ve olası güçlükleri tespit edebilmek amacıyla, çalışma grubu dışındaki 4 öğretmen adayı ile pilot çalışma yapılmıştır. Bu pilot çalışma sayesinde, hem görüşme için gerekli olan süre belirlenmiş hem de görüşmede yer alan soruların sınanması da sağlanmıştır. Pilot uygulama sonunda; soruların öğretmen adaylarının seviyesine uygun ve anlaşılır olduğu araştırmacılar tarafından belirlenmiştir. Görüşme kayıtları, iki araştırmacı tarafından kodlanmış ve iki kodlama için uyuşum yüzdesi 0.88 (Miles \& Huberman, 1994) olarak hesaplanmıştır. Şencan (2005)'a göre elde edilen değerin güvenilir kabul edilebilmesi için uyuşum yüzdesinin 0.70 üzerinde olması gerekmektedir.

\section{Verilerin Analizi}

Alkol kavram testinde öğretmen adaylarının sorulara verdikleri cevaplar, "tam anlama, spesifik kavram yanılgılı kısmen anlama, spesifik kavram yanılgısı ve cevapsız" olmak üzere dört kategoriye göre değerlendirilmiştir. Görüşmeden elde edilen veriler ise, alkol kavram testinin analizinde kullanılan kategorilerle birlikte, verilen cevabın tamamını değil de, bir kısmını içerdiği durumlar için kullanılan "kısmen anlama" kategorisi ve kavram testindeki cevapsız kategorisi yerine "anlamama" kategorisinin dikkate alınmasıyla analiz edilmiştir. Anlamama kategorisinde, öğretmen adaylarının "bilmiyorum, bu soruyu geçelim” şeklindeki cevapları yer almaktadır. En son aşamada ise bu veriler yüzde ve frekans olarak sunulmuştur. 


\section{Bulgular ve Yorumlar}

$\mathrm{Bu}$ bölümde, alkoller konusu kavram testi ve yarı yapılandırılmış görüşmeden elde edilen bulgulara yer verilmiştir.

\section{Alkoller Konusu Kavram Testine Ait Bulgular}

Öğretmen adaylarının kavram testinde verdikleri cevaplarının yüzde değerleri Tablo 3'te gösterilmiştir. Kavram testindeki tüm sorularda, spesifik kavram yanılgısını içeren üç seçenek olduğu için, Tablo 3'te bu üç ayrı seçeneğe ait yüzde değerleri sunulmuştur. Tablo 4'de ise her bir soruda saptanan spesifik kavram yanılgılarından oranı \%6 ve üzerinde olanlara yer verilmiştir. Haslam ve Tregaust (1987), örneklemin \%10 ve üzerini temsil eden kavram yanılgılarını anlamlı kabul edilmiştir, ancak kavram testinde her sorudan en az bir spesifik kavram yanılgısının temsil edilebilmesi için araştırmada bu değer \%6 olarak alınmıştır.

Tablo 3 Öğretmen Adaylarının Kavram Testinde Verdikleri Cevapların Yüzdeleri

\begin{tabular}{ccccccc}
\hline Soru & T.A (\%) & SKYKA (\%) & SKY (\%) & SKY (\%) & SKY (\%) & Cevapsiz \\
\hline 1. Soru & 58 & 21 & 6 & 3 & 3 & 9 \\
2. Soru & 45 & 13 & 19 & 12 & 3 & 8 \\
3. Soru & 40 & 8 & 14 & 12 & 13 & 13 \\
4. Soru & 36 & 14 & 26 & 10 & 9 & 5 \\
5. Soru & 35 & 5 & 21 & 14 & 13 & 12 \\
6. Soru & 43 & 9 & 18 & 16 & 10 & 4 \\
7. Soru & 53 & 5 & 22 & 8 & 5 & 7 \\
8. Soru & 48 & 5 & 26 & 4 & 3 & 14 \\
9. Soru & 34 & 10 & 14 & 22 & 10 & 10 \\
10. Soru & 43 & 12 & 19 & 13 & 3 & 10 \\
11. Soru & 46 & 9 & 9 & 23 & 4 & 9 \\
12. Soru & 42 & 8 & 18 & 9 & 5 & 18 \\
13. Soru & 47 & 14 & 8 & 8 & 9 & 14 \\
14. Soru & 43 & 13 & 14 & 12 & 6 & 12 \\
15. Soru & 44 & 13 & 13 & 12 & 9 & 9 \\
16. Soru & 35 & 13 & 15 & 10 & 10 & 17 \\
\hline
\end{tabular}

Tablo 4 Kavram Testinde Saptanan Spesifik Kavram Yanılgıları ve Yüzdeleri

\begin{tabular}{llc}
\hline Soru & Kavram Yanılgısı & $\%$ \\
\hline 1. Soru & $\begin{array}{l}\text { Aynı karbon sayılı bir monoalkol, dialkol ve eterin kaynama noktaları, karbon } \\
\text { sayıları aynı olduğu için birbirine eşittir. }\end{array}$ & 6 \\
2. Soru & Tüm mono alkoller $\mathrm{C}_{\mathrm{n}} \mathrm{H}_{2 \mathrm{n}+2} \mathrm{O}$ kapalı formülü ile gösterilir. & 19 \\
2. Soru & Sadece eterler $\mathrm{C}_{\mathrm{n}} \mathrm{H}_{2 \mathrm{n}+2} \mathrm{O}$ kapalı formülü ile gösterilir. & 12 \\
3. Soru & Bir molekülün alkol olması için hidroksil grubu (-OH) taşıması yeterlidir.* & 14 \\
3. Soru & Halkalı yapılar, alkol özelliği taşımaz & 12 \\
3. Soru & Bir molekülün alkol olması için molekülde $\pi$ bağı olmamalıdır & 13 \\
4. Soru & C sayısının artması alkollerin sudaki çözünürlüğünü artırır. & 26 \\
4. Soru & Dallanmanın artması alkollerin sudaki çözünürlüğünü azaltır. & 10 \\
4. Soru & Farklı karbon sayılı sekonder alkollerin çözünürlüğü, primer alkollerden fazladır. & 9
\end{tabular}




\begin{tabular}{|c|c|c|}
\hline 5.Soru & Aynı karbon sayılı düz ve dallanmıș alkollerin sudaki çözünürlükleri aynıdır. & 21 \\
\hline 5. Soru & $\begin{array}{l}\text { Birbirinin izomeri olan tersiyer ve sekonder alkolden, tersiyer alkolün sudaki } \\
\text { çözünürlüğü sekonder alkolden daha azdır }\end{array}$ & 14 \\
\hline 5. Soru & $\begin{array}{l}\text { Birbirinin izomeri olan tersiyer ve primer alkolden, tersiyer alkolün sudaki } \\
\text { çözünürlüğ̈̈ primer alkolden daha azdır }\end{array}$ & 13 \\
\hline 6. Soru & Bütün alkollerin eter izomerisi vardır. & 18 \\
\hline 6. Soru & Sadece trioller eter ile izomerdir. & 16 \\
\hline 6. Soru & Sadece diollerin eter izomerisi vardır & 10 \\
\hline 7.Soru & $\begin{array}{l}\text { Sadece mono alkoller, primer alkol özelliği taşır; diol ve trioller primer alkol } \\
\text { özelliği taşımaz. }\end{array}$ & 22 \\
\hline 7.Soru & $\begin{array}{l}\text { Bir alkolün, primer alkol özelliği taşıyabilmesi için; hidroksil grubunun bağlı } \\
\text { olduğu karbon atomuna bir hidrojen atomu bağlanmalıdır. }\end{array}$ & 8 \\
\hline 8. Soru & $\begin{array}{l}\text { Karbon zincirinde } \mathrm{C}=\mathrm{C} \text { olması durumunda öncelik, hidroksil grubunda değil } \mathrm{C}=\mathrm{C} \\
\text { 'dadır ve adlandırma alkene göre yapılır. }\end{array}$ & 26 \\
\hline 9. Soru & Metalik sodyumla sadece primer alkoller tepkime verir. & 22 \\
\hline 9. Soru & Metalik sodyumla sadece sekonder alkoller tepkime verir. & 14 \\
\hline 9. Soru & Metalik sodyumla sadece tersiyer alkoller tepkime verir & 10 \\
\hline 10. Soru & Lucas ayıracı ile en hızlı tepkimeyi primer alkoller verir. & 19 \\
\hline 10. Soru & Lucas ayıracı ile en hızlı tepkimeyi sekonder alkoller verir & 13 \\
\hline 11.Soru & Sikloheksanol halkalı yapıdaki bir alkol olduğundan yükseltgenmez. & 9 \\
\hline 11. Soru & $\begin{array}{l}\text { Bir primer alkol olan sikloheksanolün yükseltgenmesi ile bir keton olan } \\
\text { sikloheksanon oluşur }\end{array}$ & 23 \\
\hline 12. Soru & $\begin{array}{l}\text { Etil alkolün } 2 \text { molünden, } 140^{\circ} \mathrm{C} \text { de } \mathrm{H}_{2} \mathrm{SO}_{4} \text { varlı̆̆ında } 1 \mathrm{~mol} \text { su çekilmesiyle ana } \\
\text { ürün olarak } 1 \text { mol eten elde edilir. }\end{array}$ & 18 \\
\hline 12. Soru & $\begin{array}{l}\text { Etil alkolün } 2 \text { molünden, } 140^{\circ} \mathrm{C} \text { de } \mathrm{H}_{2} \mathrm{SO}_{4} \text { varlığında } 1 \mathrm{~mol} \text { su çekilmesiyle ana } \\
\text { ürün olarak } 2 \text { mol eten elde edilir. }\end{array}$ & 9 \\
\hline 13. Soru & Sekonder alkoller yükseltgenmez. & 9 \\
\hline 13. Soru & Tersiyer alkolün yükseltgenmesi ile keton oluşur. & 8 \\
\hline 14. Soru & $\begin{array}{l}\text { 1-bromopropanın seyreltik kuvvetli bazlarla verdiği tepkimede ana ürün olarak bir } \\
\text { alken olan 1-propen elde edilir. }\end{array}$ & 14 \\
\hline 14. Soru & $\begin{array}{l}\text { 1-bromopropanın seyreltik kuvvetli bazlarla verdiği tepkimede ana ürün olarak bir } \\
\text { alkin olan 1-propin elde edilir. }\end{array}$ & 12 \\
\hline 14. Soru & $\begin{array}{l}\text { 1-bromopropanın seyreltik kuvvetli bazlarla verdiği tepkimede ana ürün olarak 1- } \\
\text { bir alkol olan propen-2-ol oluşur }\end{array}$ & 6 \\
\hline 15. Soru & Ketonların indirgenmesi ile primer alkoller oluşur & 13 \\
\hline 15. Soru & Ketonların indirgenmesi ile tersiyer alkoller oluşur. & 12 \\
\hline 15. Soru & Ketonlar indirgenmez. & 9 \\
\hline 16. Soru & Karboksilli asitlerin iki basamak indirgenmesi ile sekonder alkoller oluşur. & 15 \\
\hline 16. Soru & Karboksilli asitlerin iki basamak indirgenmesi ile tersiyer alkoller oluşur. & 10 \\
\hline 16. Soru & Karboksilli asitlerin iki basamak indirgenmesi ile eterler oluşur & 10 \\
\hline
\end{tabular}

\section{Alkollerin Fiziksel Özellikleri-Kaynama Noktası}

Kavram testindeki 1. soru ile öğretmen adaylarının aynı karbon sayılı bir mono alkol, dialkol ve eterin kaynama noktalarını, hidrojen bağının etkisini dikkate alarak karşılaştırmaları amaçlanmıştır. Tablo 3'den anlaşılacağı üzere, öğretmen adaylarının diğer tüm sorular içersinde tam anlama yüzdesinin en yüksek, spesifik kavram yanılgısının en düşük yüzdede olduğu soru 1. sorudur. Öğretmen adaylarının, hidrojen bağının kaynama noktası üzerindeki etkisini sadece Kimya IV dersi kapsamındaki alkoller konusu içersinde değil, Kimya I dersindeki moleküller arası çekim kuvvetleri kapsamında ve ortaöğretimde görmeleri bu duruma neden olmuş olabilir. Bu soruda görülen en yüksek orandaki kavram 
yanılg1s1 \%6 oranında olan "aynı karbon sayılı bir monoalkol, dialkol ve eterin kaynama noktaları, karbon sayıları aynı olduğu için birbirine eşittir” yanılgısındadır.

\section{Alkollerin Genel Özellikleri}

Alkollerin genel özellikleri ile ilgili olarak kavram testinde 2. soru hazırlanmıştır. Tablo 3 incelendiğinde, öğretmen adaylarının \%45'i tam anlama kategorisinde yer alırken, spesifik kavram yanılgısı kategorisinde de \%34 gibi yüksek bir oranın olduğu görülmektedir. $\mathrm{Bu}$ kavram yanılgılarından en yüksek oran \%19 ile "tüm mono alkoller $\mathrm{C}_{n} \mathrm{H}_{2 n+2} \mathrm{O}$ kapalı formülü ile gösterilir” yanılgısındadır. Bu sonuç, bu cevabı veren öğretmen adaylarının karbon zincirinin $\pi$ bağı içermesi durumunu ya da molekülün halkalı yapıda olmasını dikkate almadıklarını, moleküllerin içerdiği hidroksil grubu sayısına göre bir yorum yaptıklarını göstermektedir. Dikkat çeken bir diğer kavram yanılgısı (\%12) ise, "sadece eterlerin bu kapalı formüle uyacă̆ına" inanılmasıdır.

\section{Alkol Olma Koşulları}

Kavram testindeki 3. soru ile öğretmen adaylarının alkol molekülünü tanıyıp tanımadıklarının tespit edilmesi amaçlanmıştır. Tablo 3'ten de görüldüğü gibi, öğretmen adaylarının \%40’` tam anlama kategorisinde yer almışlardır. Öğretmen adaylarından spesifik kavram yanılgısı seçeneklerini seçenler ise \%39 gibi son derece yüksek bir orandadır. Bu kavram yanılgılarından özellikle "bir molekülün alkol olması için hidroksil grubu (-OH) taşıması yeterlidir” seçeneğini seçenlerin oranı \%14'tür. Bir diğer spesifik kavram yanılgısı ise, \%13 oranında olan "halkalı yapıların alkol özelliği taşıyamayacağıdır”. Bu yanılgı öğretmen adaylarının daha çok düz ya da dallanmış karbon zincirli alkol molekülleri ile karşılaşmalarından kaynaklanabilir. Öğretmen adaylarının \%12'si ise “molekülde $\pi$ bă̆ olması durumunda o molekülün alkol olamayacağına” inanmaktadır. Bu kavram yanılgısı, öğretmen adaylarının, bir molekülün alkol olabilmesi için hidroksil grubunun bağlı olduğu karbon atomunun $\pi$ bağı içermemesi gerektiği bilgisini, tüm molekülde $\pi$ bağı olmamalıdır biçiminde genellemelerinin bir sonucu olabilir.

\section{Alkollerin Fiziksel Özellikleri-Çözünürlük}

Alkollerin çözünürlüğü ile ilgili kavram testinde 2 soru yer almaktadır. Bunlardan 4. soruda, 4 karbonlu primer bir mono alkol, 12 karbonlu sekonder bir mono alkol ve etandiolün sudaki çözünürlüklerini hidrojen bağ sayısı ve karbon sayısına bağlı olarak karşılaştırmaları istenmiştir. Tablo 3 incelendiğinde, öğretmen adaylarının \%36'sının tam anlama, \%45'inin de spesifik kavram yanılgısı kategorisine giren cevapları verdikleri görülmektedir. Öğretmen 
adaylarında en yüksek oranda saptanan kavram yanılgıs1 \%26 ile " $C$ sayısının artması, alkollerin çözünürlüğünü arttıracağına inanılmasıdır’. Bu yanılgının bu kadar yüksek bir oranda görülmesi, öğretmen adaylarının alkollerin fiziksel özellikleri başlığı altında işlenen kaynama noktası ile sudaki çözünürlüklerini benzer bir şekilde yorumlamalarından kaynaklanabilir. İkinci en yüksek orandaki kavram yanılgısı ise $\% 10$ oranındaki “dallanmanın artması alkollerin sudaki çözünürlüğünü azaltır” yanılgısıdır. Bu cevabı veren öğretmen adayları, hidroksil grubunun karbon zincirinin farklı noktalarına bağlanmasını dallanma olarak kabul etmiş ve tıpkı kaynama noktasında olduğu gibi molekülde dallanma arttıkça, Van Der Waals çekim kuvvetinin azalmasının bir sonucu olarak sudaki çözünürlüklerinin de azalacağına inanmışlardır. Yani, alkollerin kaynama noktasına ilişkin var olan bilgilerini genelleyerek çözünürlük üzerinde uygulamışlardır. Bu yüzden de etandiolün sudaki çözünürlüğünü en az olarak kabul etmişlerdir. Bir diğer kavram yanılgısında ise öğretmen adaylarının \%9’u “farklı karbon sayılı sekonder alkollerin sudaki çözünürlüğünün, primer alkollerden fazla olduğunu” belirtmişlerdir.

Kavram testinin 5. sorusunda ise öğretmen adaylarının birbirin izomeri olan 1-bütanol, 2-metil-1-propanol ve 2-metil-2-propanol'ün sudaki çözünürlüklerinin karşılaştırmaları istenmiştir. Öğretmen adaylarının \%35'i bu soruya tam anlama kategorisinde cevap verirken, \%48'i ise spesifik kavram yanılgısı kategorisinde yer almıştır. Bunlardan "aynı karbon sayılı düz ve dallanmış alkollerin sudaki çözünürlükleri aynıdır” yanılgıs1 \%21 ile en yüksek olanıdır. Bu yanılgıya sahip öğretmen adaylarının, sadece molekül formülüne bakarak yorum yaptıkları anlaşılmaktadır. Diğer kavram yanılgılarında ise öğretmen adayları, 4. soruda olduğu gibi sudaki çözünürlüğü, kaynama noktası gibi ele almışlardır. Öğretmen adaylarının \%14'ü “birbirinin izomeri olan tersiyer ve sekonder alkolden, tersiyer alkolün sudaki çözünürlüğ̈̈ sekonder alkolden”, \%13 ise “birbirinin izomeri olan tersiyer ve primer alkolden, tersiyer alkolün sudaki çözünürlüğü primer alkolden daha az" olduğunu ifade etmiştir.

\section{Yapısal İzomeri}

Kavram testindeki 6. soru ile aynı karbon sayısına sahip mono alkoller ile mono eterlerin birbirinin yapı izomerisi olduğunun ifade edilmesi amaçlanmıştır. Tablo 3 göstermektedir ki, öğretmen adaylarının \%43'ü, sadece mono alkollerin mono eterler ile izomeri olabileceğini doğru bir şekilde kavramıştır. Spesifik kavram yanılgısı kategorisinde ise öğretmen adaylarının \%18'i “bütün alkollerin eter izomerisi olduğu”, \%16's1 "sadece triollerin eter izomerisi olduğu" ve \%10'u ise "sadece diollerin eter izomersi olduğu" 
seçeneklerini seçtikleri görülmektedir. Bu yanılgılar, öğretmen adaylarının yapı izomerisi konusunda anlama düzeylerinin yeterli olmamasından ya da eterlerin molekül ve yap1 formüllerini tam olarak bilmemelerinden kaynaklanabilir.

\section{Alkol çeşitleri}

Öğretmen adaylarının alkolleri sınıflandırmasına ilişkin anlama düzeyleri ve kavram yanılgılarını ortaya koymak amacıyla kavram testinde 7 . soru hazırlanmıştır. Tablo 3 'den de anlaşılacağı üzere öğretmen adaylarının 1. sorudan sonra en yüksek tam anlama yüzdesine (\%53) sahip oldukları soru 7. sorudur. Ancak spesifik kavram yanılgısı kategorisi içersinde de yüksek yüzdeli kavram yanılgılarının olduğu görülmektedir. Bunlar içersinde en yüksek yüzde ise \%22 ile "sadece mono alkoller, primer alkol özelliği taşır; diol ve trioller primer alkol özelliği taşımaz” yanılgısındadır. Bu yanılgının temel nedenlerinden biri, öğretmen adaylarının primer alkol sınıflandırmasını tam olarak kavrayamaması ya da örnek olarak karşılaştıkları primer alkollerin çoğunlukla mono alkol olması olabilir. Bir diğer spesifik kavram yanılgısı ise \%8 oranında olan "bir alkolün, primer alkol özelliği taşlyabilmesi için; hidroksil grubunun bağll olduğu karbon atomuna bir hidrojen atomu bağlanmalıdır" şeklindedir. Bu yanılgı da öğretmen adaylarının, primer ve sekonder alkolleri birbirine karıştırdığını göstermektedir.

\section{Alkollerin Adlandırllması}

Kavram testindeki 8. soru ile öğretmen adaylarının, fonksiyonel grupların öncelik sırasını dikkate alarak bir alkol molekülünü IUPAC sistemine göre adlandırmaları amaçlanmıştır. Tablo 3 incelendiğinde öğretmen adaylarının \%48'inin verilen molekülü doğru bir şekilde adlandırarak tam anlama kategorisinde yer aldıkları görülmektedir. Bu soruda saptanan "karbon zincirinde $C=C$ olması durumunda öncelik, hidroksil grubunda değil $C=C$ 'dadır ve adlandırma alkene göre yapılır” kavram yanılgısı \%26 ile diğerlerine göre daha fazla ağırlık kazanmıştır. Bu cevabı veren öğretmen adaylarının, hidroksil grubunun ikili bağ karbon atomlarına göre daha öncelikli olduğu bilgisini kavrayamadıkları anlaşılmaktadır.

\section{Alkollerin Tepkimeleri-Sodyumla Tepkimeleri}

Öğretmen adaylarının alkollerin aktif metallerle verdikleri reaksiyonuna ilişkin anlama düzeylerini ve kavram yanılgılarını belirlemek amacıyla kavram testindeki 9. soru hazırlanmıştır. Tablo 3'den anlaşılacağı üzere, bu soruya tam anlama düzeyinde cevap verenlerin oranı \%34 gibi düşük bir düzeyde olurken, her üç spesifik kavram yanılgısı da yüksek yüzde değerlerine sahiptir. Nitekim, alkollerin sodyumla tepkimesini sadece primer 
alkol verir diyenler $\% 22$, sekonder alkoller verir diyenler $\% 14$, tersiyer alkoller verir diyenler ise $\% 10$ oranında olmuştur. $\mathrm{Bu}$ sonuç, öğretmen adaylarının alkollerin sınıflandırılmasında kullanılan primer, sekonder ve tersiyer alkol kavramlarını kimyasal tepkime vermelerinde öncelik olarak görmelerinin bir sonucu olabilir.

\section{Alkollerin Tepkimeleri-Lucas Ayıracı}

Alkollerin önemli reaksiyonlarından biri olan ve birbirinin izomeri olan primer, sekonder ve tersiyer alkollerin ayırt edilmesinde kullanılabilen Lucas ayıracı reaksiyonları ile ilgili olarak kavram testinde 10. soru hazırlanmıştır. Tablo 3 incelendiğinde, öğretmen adaylarının \%43'ünün bu soruyu tam anlama kategorisinde cevapladıkları görülmektedir. Bunun yanında \%19 oranında olan "Lucas ayıracı ile en hızl tepkimeyi primer alkoller verir" ve \%13 oranında olan "Lucas ayıracı ile en hızlı tepkimeyi sekonder alkoller verir" kavram yanılgıları da tıpkı alkollerin metalik sodyumla olan reaksiyonunda olduğu gibi, öğretmen adaylarının primer ve sekonderin kelime anlamının birincil ve ikincil olmasını temel almalarından kaynaklanabilir.

\section{Alkollerin Tepkimeleri- Yükseltgenme}

Alkollerin yükseltgenmeleri ile ilgili olarak kavram testinde iki soru bulunmaktadır. Bunlardan biri olan 11. soruda, bir sekonder alkol olan sikloheksanolün yükseltgenme reaksiyonu sorulmuştur. Öğretmen adaylarının \%46's1 sikloheksanolün yükseltgenmesi sonucu sikloheksanon oluştuğunu belirterek tam anlama kategorisinde yer almışlardır. Spesifik kavram yanılgılarında ise en yüksek oran \%23 ile "bir primer alkol olan sikloheksanolün yükseltgenmesi ile bir keton olan sikloheksanon oluşur” yanılgısındadır. $\mathrm{Bu}$ kavram yanılgısında, öğretmen adayları hem sekonder alkolü primer alkol olarak tanımlamışlar hem de bir primer alkolün yükseltgenmesi sonucu keton oluşacağını ifade etmişlerdir. Bir diğer kavram yanılgısında ise öğretmen adaylarının \%9'u "sikloheksanolün halkalı yapıdaki bir alkol olduğundan yükseltgenemeyeceğini” belirtmişlerdir. Bu yanılgıya öğretmen adaylarının halkalı yapıdaki alkol örnekleri ile çok fazla karşılaşmaması neden olmuş olabilir.

Kavram testindeki 13. soruda ise bir primer alkol olan 1- propanol'ün yükseltgenmesi sorulmuştur. Tablo 3'den öğretmen adaylarının \%47'sinin tam anlama kategorisine giren cevabı vererek bu alkolün bir basamak yükseltgenmesi ile bir aldehit olan propanalın, bir basamak daha yükseltgenmesi ile de bir karboksilli asit olan propanoik asidin oluştuğunu kavradıkları anlaşılmaktadır. Öğretmen adaylarının spesifik kavram yanılgısı içeren cevapları 
incelendiğinde (Tablo 4) ise, 11. soruda olduğu gibi öğretmen adaylarının hem alkollerin yükseltgenmesini hem de verilen alkol molekülünün türünü doğru olarak kavrayamadıkları görülmektedir. Öğretmen adaylarının \%9'unun “l-propanol’ü sekonder alkol olarak tanımlayıp ve sekonder alkollerin yükseltgenmeyeceğini” ifade etmesi bu duruma örnek olan spesifik kavram yanılgılarından biridir. Bir diğer spesifik kavram yanılgısı ise "tersiyer alkol olan 1-propanol'ün yükseltgenmesi ile ketonların oluşacă̆ı" yanılgısıdır. Öğretmen adaylarının \%8'inde bu kavram yanılgısı mevcuttur.

\section{Alkollerin Tepkimeleri-Dehidrasyon}

Alkollerin dehidrasyon tepkimesi ile ilgili olarak kavram testindeki 12. soru hazırlanmıştır. $\mathrm{Bu}$ soru ile alkollerden farklı sıcaklıklarda su çekilmesi ile farklı ürünlerin oluşabileceğinin ayırt edilmesi amaçlanmıştır. Tablo 3'den öğretmen adaylarının \%42'sinin, bu soruda ana ürün olarak eter oluşacağını ifade ederek tam anlama kategorisinde cevap verdiği anlaşılmaktadır. Buna karşın öğretmen adaylarının verdikleri cevaplardan \%18 oranında olan “etil alkolün 2 molünden, $140^{\circ} \mathrm{C}$ de $\mathrm{H}_{2} \mathrm{SO}_{4}$ varliğında 1 mol su çekilmesiyle ana ürün olarak 1 mol eten elde edilir" ve \%9 oranında olan "etil alkolün 2 molünden, $140{ }^{\circ} \mathrm{C}$ de $\mathrm{H}_{2} \mathrm{SO}_{4}$ varlı̆̆ında $1 \mathrm{~mol}$ su çekilmesiyle ana ürün olarak 2 mol eten elde edilir" spesifik kavram yanılgıları öğretmen adaylarının alkollerden farklı koşullarda su çekildiğinde oluşacak ürünleri ayırt edemediğini, sadece alken eldesi ile ilişkilendirebildiklerini göstermektedir.

\section{Alkollerin Eldesi-Alkil Halojenürlerin Nükleofilik Yer Değiştirme Reaksiyonu}

Kavram testinde, alkollerin eldesi ile ilgili olarak ikisi indirgenme reaksiyonu (15 ve 16. sorular), biri alkil halojenürlerin nükleofilik yer değiştirme reaksiyonu (14.soru) olmak üzere üç soru bulunmaktadır. Bunlardan 14. soru ile ilgili olarak Tablo 3 göstermektedir ki, öğretmen adaylarının \%43'ü 1-bromopropanın seyreltik KOH ile verdiği tepkimede ana ürün olarak 1-propanolün oluşacağını doğru bir şekilde de açıklamışlar ve tam anlama kategorisi yer almışlardır. Aynı zamanda Tablo 4'den soru ile ilgili spesifik kavram yanılgıları incelendiğinde, öğretmen adaylarının alken ve alkin eldesi ile alkol eldesini birbirine karıştırdıkları anlaşılmaktadır. Nitekim öğretmen adaylarında en yüksek oranda (\%14) görülen kavram yanılgısı olan "1-bromopropanın seyreltik $\mathrm{KOH}$ ile verdiği tepkimede ana ürün olarak bir alken olan 1-propen oluşur” yanılgısı öğretmen adaylarının, bu reaksiyonu eliminasyon reaksiyonun olarak ele aldıklarını göstermektedir. Öğretmen adaylarının \%12'si ise, alkinlerin, alkil dihalojenürlerden elde edilebileceği bilgisini yanlış uygulayarak, “1bromopropanın seyreltik $\mathrm{KOH}$ ile verdiği tepkimede ana ürün olarak bir alkin olan 1-propin 
oluşur" yanılgısına düşmüşlerdir. Bir diğer spesifik kavram yanılgısında ise öğretmen adaylarının \%6's1 “1-bromopropanın seyreltik $\mathrm{KOH}$ ile verdiği tepkimede ana ürün olarak bir alkol olan propen-2-ol oluşur” biçiminde bilimsel bir doğruluğu olmayan bir açıklamayı seçmişlerdir.

\section{Alkollerin Eldesi-Karbonil Bileşiklerinin İndirgenmesi}

Alkollerin, karbonil bileşiklerinin indirgenmesi yoluyla eldesi ile ilgili olarak hazırlanan 15. soruda bir keton olan 3-metil-2-pentanon'un indirgenmesi sorulmuştur. Tablo 3'den öğretmen adaylarının \%44'ünün bu soruyu tam anlama kategorisinde cevapladıkları anlaşılmaktadır. Tablo 4'den soruda saptanan spesifik kavram yanılgıları incelendiğinde ise öğretmen adaylarının özellikle, ketonların indirgenme reaksiyonunu tam olarak uygulayamadıkları ve oluşan alkol molekülünü yanlış sınıflandırdıkları anlaşılmaktadır. Örneğin, öğretmen adaylarının \%13'ü “ketonların indirgenmesi ile primer alkoller oluşur”, $\% 12$ 'si ise "ketonların indirgenmesi ile tersiyer alkoller oluşur" yanılgılarına sahiptir. Öğretmen adaylarının \%9'unda ise “ketonların indirgenemeyeceği”" spesifik kavram yanılgısı saptanmıştır.

Alkollerin eldesi ile ilgili olan üç soru içersinde öğretmen adaylarının tam anlama yüzdesinin \%35 ile en düşük olduğu soru kavram testinin 16. sorusu olmuştur. Bu soruda öğretmen adaylarından pentanoik asidik yapı formülünü yazıp, daha sonra indirgenme reaksiyonu sonucu oluşacak ürünü yazmaları istenmiştir. $\mathrm{Bu}$ sonuç, öğretmen adaylarının verilen moleküllerin sembolik gösterimlerinde zorlanmalarından kaynaklanabilir. Ayrıca, soruda saptanan spesifik kavram yanılgılarından, öğretmen adaylarının, karboksilli asitlerin indirgenmesi sonucu oluşan alkolleri de yanlış sınıflandırdıkları belirlenmiştir. Nitekim, öğretmen adaylarının \%15'i “karboksilli asitlerin iki basamak indirgenmesi ile sekonder alkollerin oluştuğunu”, \%10’u ise "tersiyer alkollerin oluştuğunu” belirtmiştir. Öğretmen adaylarının \%10'u ise "karboksilli asitlerin iki basamak indirgenmesi ile eterler oluşur" şeklinde bir spesifik kavram yanılgısına sahiptirler.

\section{Görüşmeden Elde Edilen Bulgular}

Öğretmen adaylarının görüşme sorularına verdikleri cevapların kategorilere göre dağılımı Tablo 5'de sunulmuştur.

Tablo 5 Öğretmen Adaylarının Görüşme Sorularına Verdikleri Cevapların Frekans Değerleri

\begin{tabular}{llllll}
\hline Soru & T.A & K.A & S.K.K.A & S.K.Y & Anl. \\
\hline 1. Soru & 6 & 5 & - & 1 & - \\
2. Soru & 4 & 3 & - & 3 & 2 \\
\hline
\end{tabular}




\begin{tabular}{llllll}
\hline 3. Soru & 3 & - & 4 & 1 & 4 \\
4.a) Soru & 2 & 3 & - & 3 & 4 \\
4.b) Soru & 3 & - & 1 & 4 & 4 \\
4.c) Soru & 3 & - & - & 6 & 3 \\
\hline
\end{tabular}

Birinci Görüşme Sorusu: Açık formülü verilen bir molekülün alkol olduğunu nasıl anlarsınız? Örnek vererek açıklar mısınız?

Görüşmede yer alan bu soru ile öğretmen adaylarının alkol olma koşullarını açıklamaları istenmiştir. Tablo 5 incelendiğinde, öğretmen adaylarının 6'sı tam anlama, 5'i kısmen anlama, 1'i ise spesifik kavram yanılgısı kategorisine giren cevapları verdikleri görülmektedir. Tam anlama kategorisine giren cevaplar incelendiğinde, öğretmen adaylarının bir molekülün kararlı yapıda bir alkol olabilmesi için hidroksil (-OH) grubunun bağlı olduğu $\mathrm{C}$ atomumun $\mathrm{sp}^{3}$ hibritleşmesi yapması gerektiğini ve aynı $\mathrm{C}$ atomuna birden fazla hidroksil grubunun bağlanamayacağını ifade ettikleri saptanmıştır. Bu kategoriye giren öğretmen adaylarının cevaplarından bazı alıntılar aşağıda sunulmuştur:

A: Açık formülü verilen bir molekülün alkol olduğunu nasıl anlarsınız? Örnek vererek açıklar mısınız?

Ö5: Hidroksil grubu içermelidir.

A: Molekülün yapısında hidroksil grubunun olması yeterli midir?

Ö5: Hayır. Hidroksil grubunu tespit ettikten sonra bağlı olduğu karbon atomunun sp ${ }^{3}$ hibritleşmesi yapıp yapmadı̆̆ına bakmalıyız. Örneğin,

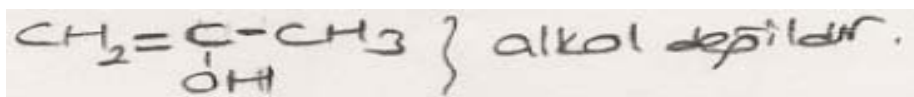

Bileşiği alkol değildir. Çünkü -OH’ın bağlandı̆̆ı karbon atomu sp ${ }^{2}$ yapmıştır. Ancak şu bileşik,

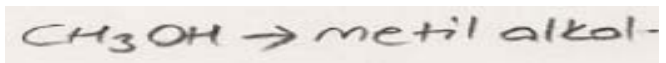

alkoldür. Çünkü $s p^{3}$ hibritleşmesi vardır. Bir de aynı karbon atomuna sadece bir tane hidroksil grubu bă̆landı̆̆ında molekül alkoldür. Yoksa değildir. Bunlara uyan bütün moleküller alkoldür.

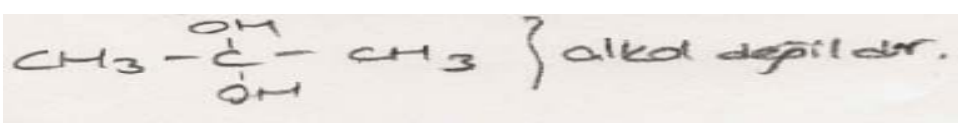

Bu yüzden bu molekül alkol değildir. İki tane hidroksil grubu aynı karbon atomuna bağlanmıştır.

Kısmen anlama kategorisinde ise öğretmen adayları, alkol olma koşullarından sadece birini açıklamaktadırlar. Özellikle, bu öğretmen adayları, molekülde hidroksil grubun bulunmasını o molekülün alkol olması için yeterli olduğunu düşünmektedirler. Ancak, öğretmen adaylarının eksik olan bu kavramaları kavram testinde "bir molekülün alkol olması için hidroksil grubu (-OH) taşıması yeterlidir” biçiminde \%14 gibi yüksek bir oranda spesifik kavram yanılgısı olarak ortaya çıkmıştır. Bu kategoride yer alan öğretmen adaylarının cevaplarından bazı alıntılar aşağıda sunulmuştur:

A: Açık formülü verilen bir molekülün alkol olduğunu nasıl anlarsınız? Örnek vererek açıklar mısınız? 
Ö8: Alkollerde, açık formülde karbon zincirine bağlı hidroksil (-OH) grubu olmalıdır. Mesela bu bileşik bir alkoldür. Çünkü hidroksil grubu C atomuna bağlldır.

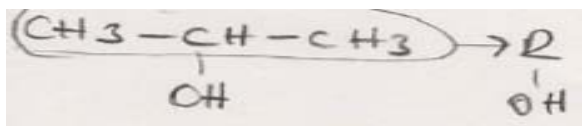

A: Karbon atomuna hidroksil grubunun bağlanması, her zaman o molekülün alkol olduğunu gösterir mi? Ö8: Alkol demek hidroksil grubu demek. Yani onu alkol yapan gruptur. Öncelikle o olmalıdır. Ancak.... Sanırım her zaman değil. Tam hatırlayamıyorum.

Öğretmen adaylarının spesifik kavram yanılgısı içeren cevabında ise bilimsel olarak doğru olmayan açıklamalar yer almaktadır. Bu kategoriye giren öğretmen adayına ait bazı alıntılar şöyledir:

A: Açık formülü verilen bir molekülün alkol olduğunu nasıl anlarsınız? Örnek vererek açıklar mısınız?

Ö10: Ĕger, oksijen ve hidrojen gazı ekleyerek su oluşturuyorsa, o molekül alkoldür demektir.

A: Bu ifadeyi biraz açar misın?

Ö10: Alkolün yapısında suyun bileşenleri var yani hem hidrojen hem oksijen. Bu yüzden yapıda olmalıdır.

A: Örnek vererek açılayabilir misin?

Ö10: İste metil ve etil alkol gibiler.

A: Bunların yapı formülünü yazabilir misin?

Ö10: Şu an aklima gelmiyor...

İkinci Görüşme Sorusu: Dietil eter, 1-bütanol, 1,4-bütandiol moleküllerinin, kaynama noktaları arasında nasıl bir ilişki vardır? Açıklar mısınız?

İkinci görüşme sorusunda, aynı karbon sayılı bir monoalkol, dialkol ve eterin kaynama noktalarının hidrojen bağının etkisini dikkate alınarak açıklanması hedeflenmiştir. Tablo 5 incelendiğinde, 4 öğretmen adayının tam anlama, 3'er öğretmen adayının ise kısmen anlama ve spesifik kavram kategorilerinde yer aldığı görülmektedir. Öğretmen adaylarının tam anlama kategorisine giren cevapları incelendiğinde, verilen moleküllerin yapı formüllerini doğru bir şekilde yazdıkları, kaynama noktalarını kıyaslarken moleküller arası çekim kuvvetlerini dikkate aldıkları görülmektedir. Bu kategoride yer alan öğretmen adaylarının açıklamalarından bazı alıntılar şöyledir:

A: Dietil eter, 1-bütanol, 1,4-bütandiol moleküllerinin, kaynama noktaları arasında nasıl bir ilişki vardır? Açıklar misinız?

Ö6: 3. molekülün en yüksektir. Bundan sonra 2. molekül gelir. En düşük ise 1. molekülün yani eterindir.

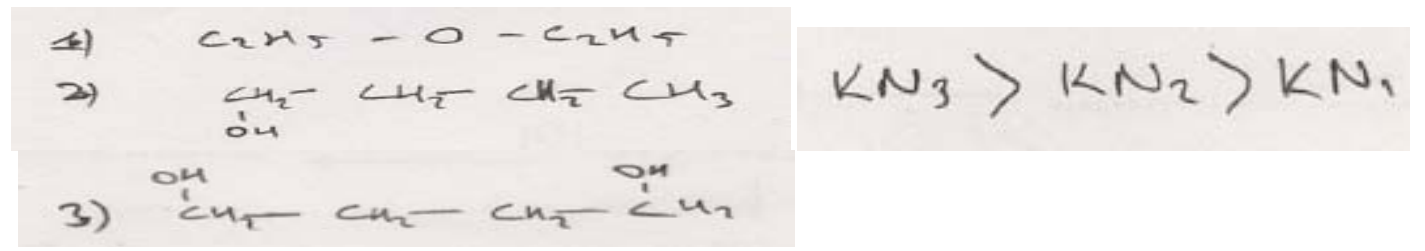

A: Bunu biraz daha açıklar mısın? 
Ö6: Kaynama noktaları kıyaslanırken, Hidrojen bă̆ına, Karbon sayısına ve dallanmaya bakılır. Bu üç molekülde aynı sayıda C atomu içeriyor. Yani üçü de dört karbon atomu içeriyor. Ama içerdikleri hidrojen bă̆ı sayısı farklı.

A: Bunu verilen örnekleri üzerinde biraz daha açıklar mısın?

Ö6: 2. ve 3. moleküller bir alkol olduğu için yapılarında hidrojen bă̆l vardır. Hidrojen bă̆l zor kopan bir bă̆ olduğundan kaynama noktasının yükselmesine neden olur. Ayrıca hidrojen bă̆ sayısı artıkça da kaynama noktası artar. Bu yüzden de, 3. molekülde daha fazla hidrojen bă̆ı olduğundan diğer alkol molekülünden daha yüksek kaynama noktasına sahiptir. Aynı karbon sayılı eterin kaynama noktasinın ise daha düşük olmasının nedeni hidrojen bağının bulunmamasıdır. Eterde dipol-dipol ve Van Der Waals çekim kuvvetleri vardır ancak bunlar hidrojen bă̆ından daha zayıftır.

Öğretmen adaylarının kısmen anlama kategorisinde yer alan cevaplarına bakıldığında, verilen moleküllerin kaynama noktalarını doğru karşılaştırmalarına karşın bunu nedenini tam olarak açıklayamadıkları, moleküller arası çekim kuvvetleri ile bağlantı kuramadıkları görülmektedir. Bu kategoride yer alan öğretmen adaylarına ait alıntılar aşağıdaki gibidir:

A: Dietil eter, 1-bütanol, 1,4-bütandiol moleküllerinin, kaynama noktaları arasında nasıl bir ilişki vardır? Açıklar mısınız?

Ö7: Kaynama noktalarını büyükten küçüğe doğru sıralayacak olursak, 1,4-bütandiol'ün kaynama noktası en yüksek, sonra 1-bütanol, sonra dietil eter gelir.

A: Bu siralamayı nasıl yaptın biraz açıklar misın?

Ö7: Moleküllerin fiziksel özelliklerini belirleyen bağlardan dolayı.

A: Bu bağlar nelerdir? Biraz açılklar misın?

Ö7: Dipol-dipol ve hidrojen bağl gibiydi sanırım.

A: Bunlar kaynama noktasinı nasıl etkiler?

Ö7: Alkollerdeki-OH grubundan dolayı en yüksek oluyor kaynama noktası. Diğerinde yok. Băglar olarak tam aklımda yok ama. -OH grubu çok diye alkollerin fazla diyoruz onu biliyorum.

Spesifik kavram yanılgısı kategorisine giren cevaplar incelendiğinde, öğretmen adaylarının, hidrojen bağını tam olarak kavrayamadıkları ve eterlerin molekülleri arasında hidrojen bağı yaptığını kabul ettikleri ortaya çıkmıştır. Bu kategorideki açıklamalardan bazı alıntılar şöyledir:

A: Dietil eter, 1-bütanol, 1,4-bütandiol moleküllerinin, kaynama noktaları arasında nasıl bir ilişki vardır? Açıklar mısınız?

Ö12: Sıralamayı eğer büyükten küçüğe doğru yaparsak $a, b$ ve c şeklinde olacaktır.

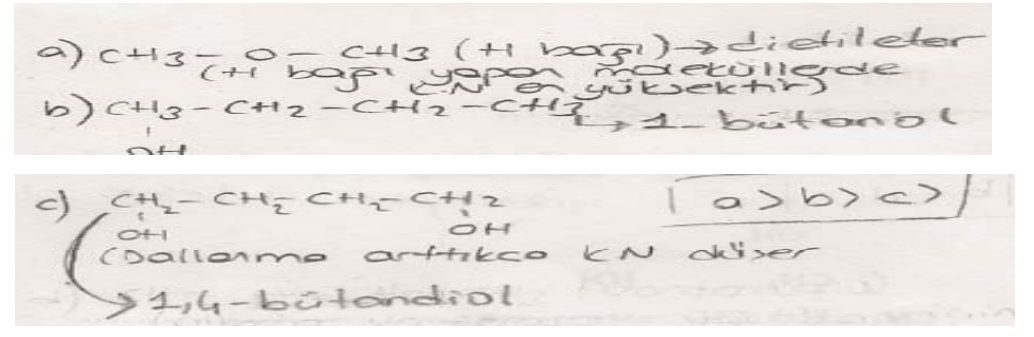

Necatibey Eğitim Fakültesi Elektronik Fen ve Matematik Eğitimi Dergisi

Necatibey Faculty of Education, Electronic Journal of Science and Mathematics Education 
A: Bu sıralamayı neye göre yaptı̆̆ını biraz açıklar mısın?

Ö12: Dietil eterde hidrojen bă̆l vardır. Diğerlerinde yoktur. Hidrojen bă̆l yapan moleküllerde de kaynama noktası en yüksektir. Diğer iki molekül için de dallanmalarına bakarak yorum yaparım. Yani 1,4 bütanol daha çok dallanmıştır. Dallanma artıkça da kaynama noktası düşer. Bu yüzden en düşük kaynama noktasina o sahiptir.

A: Hidrojen bağından bahsettin. Bir molekülün hidrojen bă̆g yapıp yapmadığını nasıl anlarız? Açıklar misin?

Ö12: Eterdeki $O$ atomu ile H arasındaki bă̆ Hidrojen bă̆ıdır.

A: Yani Hidrojen bă̆ı molekülü içinde olan bir bă̆ mıdır?

Ö12: Evet. Hidrojen ve oksijen atomları arasında elektronların ortaklaşa kullanılması ile olur.

A: Peki, alkol moleküllerinde neden hidrojen bağı yok? Bunu açıklar mısın?

Ö12: Alkolde olmaz diye biliyorum ama olabilirde hidrojen ve oksijen burada da var çünkü. Tam emin değilim.

Öğretmen adayının yaptığı bu açıklamalarda dikkat çekici önemli noktalar vardır. Bunlardan birincisi, öğretmen adayı dietil eter molekülünü, dimetil eter olarak yazmasıdır. Buradan öğretmen adayının etil ve metil gruplarını karıştırdıkları görülmektedir. Bir diğer önemli nokta ise, hidrojen bağı ile ilgilidir. Öğretmen adayı, hidrojen bağını molekül içi bir bağ olarak görmekte ve kovalent bağla karıştırmaktadır.

\section{Üçüncü Görüşme Sorusu: Şekildeki deney tüplerinde, birbirinin} yapı izomerisi olduğu bilinen etanol ve dimetil eter bulunmaktadır.

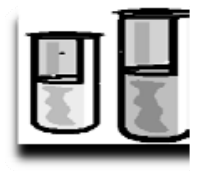

Buna göre, tüplerde bulunan bu bileşikleri ayırt etmek için hangı reaksıyonlardan yararlanılabilir? Açıklar mısınız?

Görüşmenin üçüncü sorusu, birbirinin yapı izomerisi olan alkol ve eterleri birbirinden ayırt etmek için kullanılabilecek reaksiyonlarını ortaya çıkarmak amacıyla yöneltilmiştir. $\mathrm{Bu}$ soruya ilişkin analiz sonuçları, öğretmen adaylarının sadece 3'ünün tam anlama kategorisine giren cevaplar verirken, 4'ünün spesifik kavram yanılgılı kısmen anlama kategorisinde, 1 'inin ise spesifik kavram yanılgısı kategorisinde yer aldığını göstermektedir. Tam anlama kategorisine giren öğrenci cevapları, bu öğretmen adaylarının alkoller ile eterleri birbirinden ayırt etmede kullanılabilecek reaksiyonları net bir şekilde anladıklarını göstermektedir. Dikkat çekici bir nokta ise bu kategoride yer alan öğretmen adaylarının, alkollerin tanınma reaksiyonlarına birden fazla örnek ile bu duruma açıklık getirmeleridir. Bu kategoride yer alan 3. öğretmen adayına (Ö3) ait görüşmenin ilgili kısımları aşağıda verilmiştir:

A: Şekildeki deney tüplerinde, birbirinin yapı izomerisi olduğu bilinen etanol ve dimetil eter bulunmaktadır. Buna göre, tüplerde bulunan bu bileşikleri ayırt etmek için hangi kimyasal reaksiyonlardan yararlanılabilir? Açıklar mısınız? 
Ö3: Alkollere özgü reaksiyonlara bakarı. Mesela alkoller sodyum metali ile tepkime verir. Ancak eter vermez. Alkollerin sodyumla tepkimesinde tuz ve hidrojen gazı açı̆̆a çıkar. Gaz çıkışından anlayabiliriz.

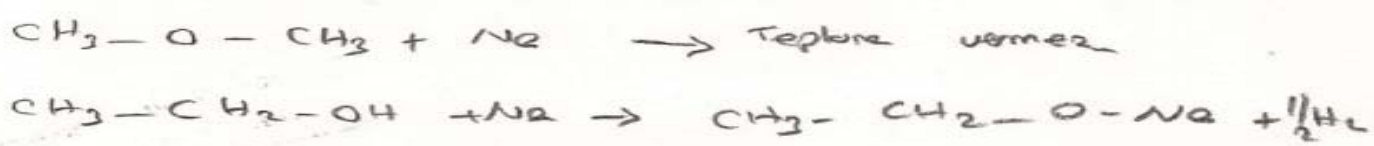

A: Sadece bu reaksiyonla mı ayırt edebiliriz? Başka reaksiyonlardan da yararlanılabilinir mi?

Ö3: Lucas ayıract ile de ayırt etme söz konusu olabilir. Alkoller Lucas ayıract ile tepkime verir ancak eterler vermezdi.

A: Lucas aylract ile neyi ifade ediyorsun? Bu reaksiyonu yazabilir misin?

Ö3: Bir çözelti, hidroklorik asit ve çinko klorür içerir. Alkolün-OH grubu ile HCl'nin klor atomu yer değiştirir.

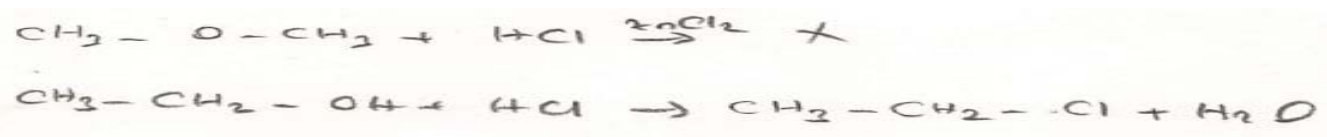

Öğretmen adaylarının, spesifik kavram yanılgılı kısmen anlama kategorisine giren cevapları incelendiğinde, etil alkol ile dimetil eteri birbirinden ayırt etmede, kimyasal reaksiyonlardan değil de kaynama noktalarından yararlandıkları ve bunu da kimyasal reaksiyon olarak gördükleri ortaya çıkmıştır. Bu duruma örnek olabilecek açıklamalarından, öğretmen adayı 10'a ait alıntılar şöyledir:

A: Şekildeki deney tüplerinde, birbirinin yapı izomerisi olduğu bilinen etanol ve dimetil eter bulunmaktadır. Buna göre, tüplerde bulunan bu bileşikleri ayırt etmek için hangi kimyasal reaksiyonlardan yararlanılabilir? Açıklar mısınız?

Ö10: Bu bileşikleri kaynama noktaları farkından bulabiliriz

A: Bunu biraz daha açıklar mısın?

Ö10: Eğer iki tüpü ısıtmaya başlarsak. Eter daha önce kaynayacaktır. Çünkü eterde dipol-dipol vardır. Yani polardır. Ancak alkolde hidrojen băğ vardır. Hidrojen bă̆l, dipol-dipolden daha kuvvetli olduğu için kaynama noktası daha yüksek olur. Bu yüzden kaynama noktası farkından ayrllır.

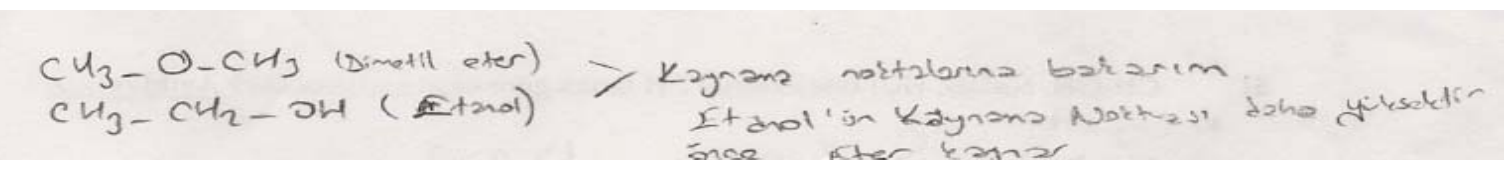

A: Burada hangi kimyasal reaksiyondan yararlanmış oluyorsun?

Ö10: Isıtma işleminden yararlandik.

A: O zaman burada isıtma ile kimyasal bir reaksiyon mu gerçekleşmiş oluyor?

Ö10: Evet. Tabii ısittnca kaynadılar. Kimyasal bir olay bu.

Görüşme yapılan öğretmen adaylarından 1 kişi, spesifik kavram yanılgısı kategorisine giren cevap vermiştir. Öğretmen adayının bu cevabı incelendiğinde, hem etanolün hem de dimetil eterin yapı formülünü doğru bir şekilde yazamadığı da saptanmıştır. Öğretmen adayının bu soruya ilişkin açıklamaları aşağıda sunulmuştur: 
A: Şekildeki deney tüplerinde, birbirinin yapı izomerisi olduğu bilinen etanol ve dimetil eter bulunmaktadır. Buna göre, tüplerde bulunan bu bileşikleri ayırt etmek için hangi kimyasal reaksiyonlardan yararlanılabilir? Açıklar mısınız?

Ö9: Bu moleküllerden etanol kararsız yapıdadır. Bu yüzden dimetil etere dönüşür.

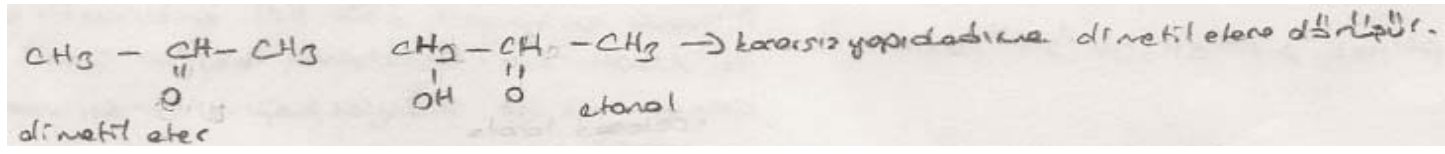

A: Etanolün kararsız yapıda olduğunu nasıl anladın?

Ö9: Çünkü $\pi$ bă̆ı var. Yapıda hem $\pi$ bağı hem de hidroksil grubu olduğunda molekül kararsız oluyordu.

A: Peki etanolün dimetil etere dönüşmesi nasıl oluyor?

Ö9: Etanole su eklersek, dimetil eter elde edilir.

A: Bu reaksiyonu yazabilir misin?

Ö9: Tam hatırlamıyorum ancak su ekliyorduk.

4. Görüşme Sorusu: Görüşmede öğrencilere yöneltilen 4. soru kendi içersinde, üç alt sorudan oluşmaktadır. Bu alt soruların her biri sırasıyla ayrı ayrı ele alınmıştır.

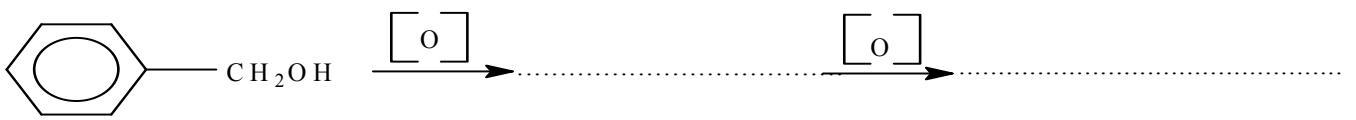

a) Reaksiyonu hangi tür reaksiyona örnek verilebilir? Bu reaksiyonda hangi ürün ya da ürünler oluşabilir?

Öğretmen adaylarından, bir primer alkol olan benzil alkolün yükseltgenmesini açıklamalarının amaçlandığı bu soruda, tam anlama kategorisinde 2 öğretmen adayı, kısmi anlama ve spesifik kavram yanılgısı kategorilerinde ise 3'er öğretmen adayı yer almıştır. Öğretmen adaylarının tam anlama kategorisine giren cevaplarından, benzil alkolün yükseltgenme reaksiyonlarında oluşan ürünleri eksiksiz olarak yazdıkları saptanmıştır. $\mathrm{Bu}$ kategoride yer alan öğretmen adayı 2(Ö2) ile yapılan görüşmeye ait alıntılar şöyledir:

A: Reaksiyonu hangi tür reaksiyona örnek verilebilir? Bu reaksiyonda hangi ürün ya da ürünler oluşabilir?

Ö2: Bu alkol bir primer alkoldür. -OH grubunun bağlı olduğu karbon atomunda 2 tane hidrojen atomu vardır. İki basamakta yükseltgenebilirler.

A: Bu reaksiyonun yükseltgenme reaksiyonu olduğu nasıl anladın?

Ö2: Organik bileşikler için yapıya oksijen katılması yükseltgenme, hidrojen katılması ise indirgenmeydi. Burada da oksijen yaptya kattllyor yani yükseltgenme.

A: Bu tepkimelerde hangi ürünler oluşur? Açıklayabilir misin?

Ö2: Birinci basamakta yükseltgenmede aldehit oluşur. Oluşan aldehitte, karboksilli aside yükseltgenir.

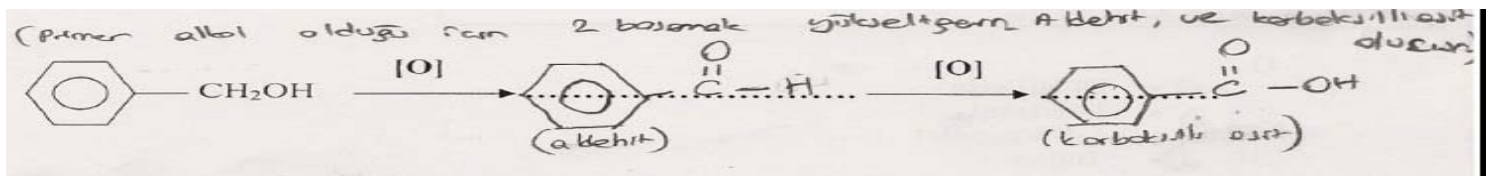


Kısmen anlama kategorisine giren cevaplar incelendiğinde, öğretmen adaylarının benzil alkolün bir primer alkol olduğunu kavradıkları, bu molekülün iki basamak yükseltgeneceğini de ifade ettikleri görülmektedir. Ancak bu öğretmen adaylarından, oluşan ürünleri yazmaları istediğinde aldehit ve karboksilli asit moleküllerini yazamadıkları saptanmıştır. Bu sonuç, öğretmen adaylarının fonksiyonel gruplu organik molekülleri tam olarak tanıyamadıklarını, ortaya çıkarmıştır. Aynı zamanda bazı öğretmen adayları da, bu tepkimenin tek basamaklı olduğunu, benzil alkolün yükseltgenmesi sonucu sadece aldehit oluşabileceğini ifade etmişlerdir. Bu kategoride yer alan öğretmen adaylarının açıklamalarına ait alıntılar aşağıda sunulmuştur:

A: Reaksiyonu hangi tür reaksiyona örnek verilebilir? Bu reaksiyonda hangi ürün ya da ürünler oluşabilir?

Ö7: Öncelikle primer bir alkoldür ve tepkime yükseltgenme tepkimesidir. İki basamakta yükseltgenir. 1 . basamakta aldehit, 2. basamakta ise karboksilli asit oluşur.

A: Yükseltgenme reaksiyonu olduğunu nasil anladın?

Ö7: Tepkimede oksijen var yani oksijen katıllyor moleküle. O yüzden yükseltgenmedir.

A: Reaksiyonda oluşan ürünleri yazabilir misin?

Ö7: Aldehit ve karboksilli asit oluşacaktır. Tam olarak hattrlamiyorum formüllerini. Sadece aldehit ve karboksilli asit oluşacak biliyorum ama açık hallerini tam bilmiyorum.

Öğretmen adaylarında, saptanan en önemli spesifik kavram yanılgısı, benzil alkolün, halkalı yapıda olduğu için yükseltgenemeyeceği yanılgısıdır. Buna benzer bir yanılgı alkol kavram testinde, sekonder bir alkol olan sikloheksanolün yükseltgenmesinde de ortaya çıkmıştır. Öğretmen adaylarının, bu kavram yanılgısına sahip olmasının başlıca nedeni, alkollerin verdikleri reaksiyonlarda daha çok düz zincirli yapılarla karşılaşmaları olabilir. Öğretmen adaylarının, spesifik kavram yanılgısı içeren cevaplarına örnek olabilecek alıntıları şöyledir:

A: Reaksiyonu hangi tür reaksiyona örnek verilebilir? Bu reaksiyonda hangi ürün ya da ürünler oluşabilir?

Ö11: Böyle bir reaksiyon olmayacakttr.

A: Neden?

Ö11: Indirgenme ve yükseltgenme tepkimesi sadece düz yapılarda gerçekleştiği için burada da gerçekleşmeyecektir.

A: Bunu biraz daha açılklar mısın?

Ö11: Alkoller yükseltgenebilir ancak halkalı yapıda ise olmaz. Yani ben bu şekilde biliyorum. Hiç halkalı bir alkolün yükseltgenmesi ile ilgili örnek hatırlamıyorum. 


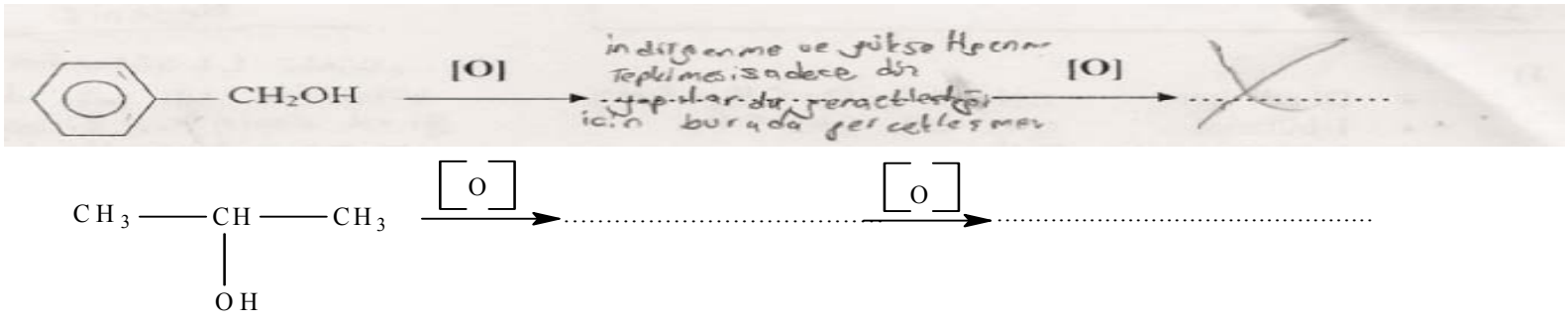

b) Reaksiyonu hangi tür reaksiyona örnek verilebilir? Bu reaksiyonda hangi ürün ya da ürünler oluşabilir?

Bir sekonder alkol olan 2-propanol'ün yükseltgenmesi ile ilgili olan bu soruda, öğretmen adaylarının 3'ü tam anlama, 1'i spesifik kavram yanılgılı kısmen anlama ve 4'ü ise spesifik kavram yanılgısı kategorisine giren cevaplar vermişlerdir. Tam anlama kategorisine giren cevaplar incelendiğinde, öğretmen adaylarının sekonder bir alkolün bir basamak yükseltgenerek ketonların oluşacağını kavradıkları ortaya çıkmıştır. Bu soruda dikkat çekici olan nokta ise, a alt maddesinde halkalı yapıdaki alkollerin yükseltgenemeyeceği biçiminde spesifik kavram yanılgısına sahip öğretmen adaylarının bu soruda tam anlama kategorisinde yer almasıdır. Bu durum da, bu öğretmen adaylarının düz zincirli yapıdaki alkollerin yükseltgenmesini kolaylıkla uygulayabildiklerini göstermektedir. Öğretmen adaylarına ait alıntılar şöyledir:

A: Reaksiyonu hangi tür reaksiyona örnek verilebilir? Bu reaksiyonda hangi ürün ya da ürünler oluşabilir?

Ö11: Bu reaksiyonun bir yükseltgenme reaksiyonu olduğunu anllyoruz. Sekonder bir alkoldür bu. Yükseltgenecektir.

A: Bu reaksiyonun yükseltgenme reaksiyonu olduğu nasıl anladın?

Ö11: Okun üstündeki oksijenden anladım. Moleküle oksijen katıllyor ise yükseltgeme, hidrojen katıllyorsa indirgenme idi.

A: Reaksiyon sonucunda hangi ürün ya da ürünler oluşacakttr.

Ö11: Sekonder alkol bir basamak yükseltgenecektir. Bunun sonucu da keton oluşur.

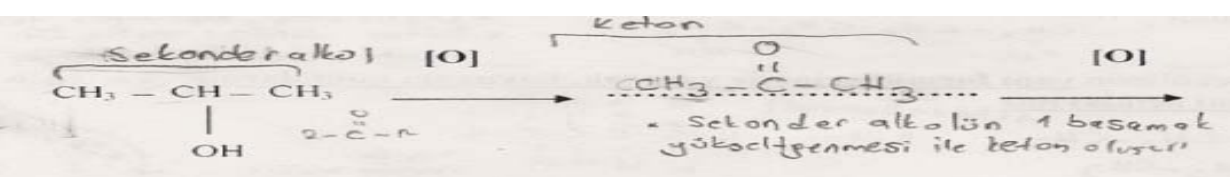

Öğretmen adaylarının verdikleri cevaplarda, spesifik kavram yanılgılı kısmen anlama kategorisinde yer alan cevabın olduğu da saptanmıştır. Bu cevapta dikkat çekici nokta, öğretmen adayının, 2-propanol'ü sekonder alkol olduğu için yükseltgenmesi ile keton oluşacağını doğru bir şekilde ifade etmesine karşın ketonun da yükseltgenebileceği biçiminde bilimsel olarak doğru olmayan bir açıklama da yapmasıdır. Öğretmen adayı 8'den alınan alıntılar şöyledir: 
A: Reaksiyonu hangi tür reaksiyona örnek verilebilir? Bu reaksiyonda hangi ürün ya da ürünler oluşabilir?

Ö8: Sekonder alkoldür, yükseltgenir önce keton yani propanon oluşur. Sonra keton da yükseltgenir.

A: Ketonun yükseltgenmesi ile ne oluşur? Bunu açıklar misın?

Ö8: Alkol oluşur. Primer bir alkoldür ancak alkin özelliği de taşır.

A: Bu durumda oluşan ürün hem alkol hem de alkin özeliliği mi taşır? Bunu biraz daha açar misın?

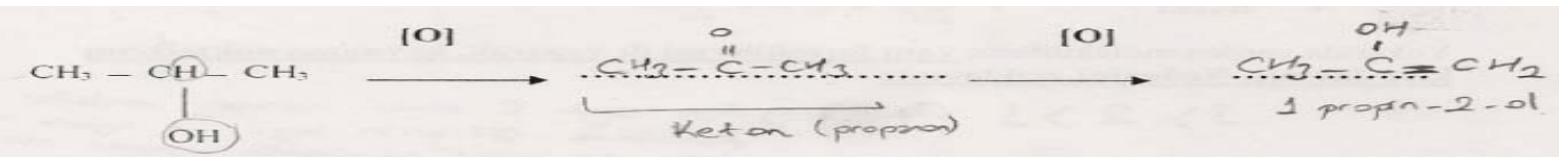

Ö8: Evet. Molekülde-OH grubu olurken, karbon atomları arasında da yeni $\pi$ bağı olur.

Yöneltilen bu soruda öğretmen adaylarında görülen en sık spesifik kavram yanılgısı ise, sekonder alkol olan 2-propanolü, primer alkol olarak yorumlayıp, yükseltgenmelerini de buna göre yorumlamalarıdır. Öğretmen adaylarının bu yanılgıya düşmelerindeki temel neden, alkolleri sınıflandırmada hataya düşmeleridir. $\mathrm{Bu}$ kategoriye giren öğretmen adayına ait alıntıların bir kısmı şöyledir:

A: Reaksiyonu hangi tür reaksiyona örnek verilebilir? Bu reaksiyonda hangi ürün ya da ürünler oluşabilir?

Ö9: 2-propanol bir primer alkoldür. İki basamakta yükseltgenecektir. Bu reaksiyonda bununla ilgilidir.

A: Bu ürünlerin neler olduğunu yazabilir misin?

Ö9: Birinci ürün aldehittir. Ancak aldehitte yükseltgenir ve karboksilli asit olur.

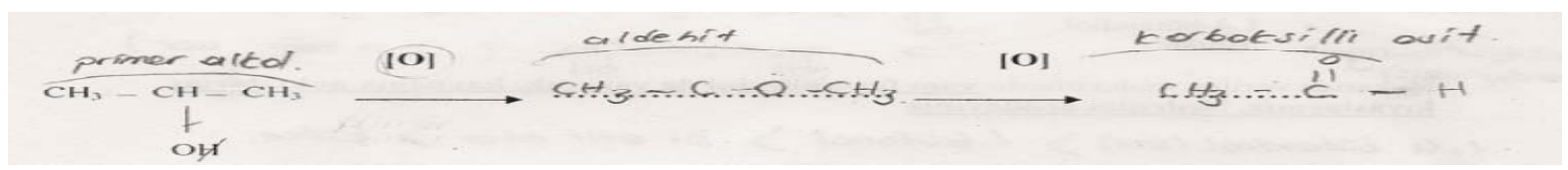

Öğretmen adayının yapmış olduğu bu açıklamadan aynı zamanda, aldehit ve karboksilli asidi tanıyamadıkları da ortaya çıkmıştır.

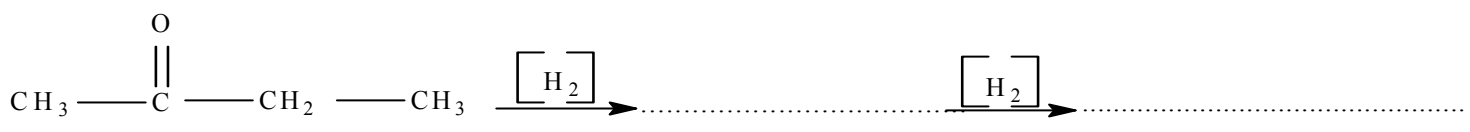

c) Reaksiyonu hangi tür reaksiyona örnek verilebilir? Bu reaksiyonda hangi ürün ya da ürünler oluşabilir?

4. görüşme sorusunun $\mathrm{C}$ alt maddesinde, öğretmen adaylarının etil metil ketonun indirgenmesi ile sekonder bir alkol olan 2-bütanol'ü yazmaları hedeflenmiştir. Öğretmen adaylarının 3'ü tam anlama, 6'sı ise spesifik kavram yanılgısı kategorisinde yer almıştır. Öğretmen adaylarının tam anlama kategorisine giren cevapları incelendiğinde, verilen tepkimenin bir indirgenme tepkimesi olduğunu kavradıkları ve reaksiyon sonunda oluşan, 2bütanol'ün yapı formülünü de doğru bir şekilde yazdıkları belirlenmiştir. Tam anlama 
kategorisine giren cevaplar içerisinde yer alan öğretmen adayı 4' e ait alıntılar şöyledir:

A: Reaksiyonu hangi tür reaksiyona örnek verilebilir? Bu reaksiyonda hangi ürün ya da ürünler oluşabilir?

Ö4: Indirgenme reaksiyonudur. Yapıya hidrojen katılıyor. Yani etil metil keton indirgenmiş oldu.

A: Tepkime sonunda ne oluştu.? Bunu biraz açıklar mısın?

Ö4: Ketonun yapısındaki karbonil grubuna hidrojenler bağlandı. Yani karbonil grubu açıldı. Bir alkol olan 2-bütanol oluştu. Yani sekonder alkol.

A: Peki reaksiyonun ikinci aşaması var mı?

Ö4: Hayır. Son aşamadır. İkinci basamak yok.

Öğretmen adaylarında en s1k görülen spesifik kavram yanılgısı, verilen keton molekülünü aldehit olarak kabul etmeleri ve bu molekülün bir basamak indirgenmesi sonucunda oluşan 2-propanol'ü primer alkol olarak tanımlamalarıdır. Aynı zamanda bazı öğretmen adayları, reaksiyonu doymamış moleküllerin hidrojenle doyurulması olarak ele almış ve alkan eldesi olarak yorumlamışladır. Bu kategoride yer alan öğretmen adaylarına ait alıntılar aşağıda sunulmuştur:

A: Reaksiyonu hangi tür reaksiyona örnek verilebilir? Bu reaksiyonda hangi ürün ya da ürünler oluşabilir?

Ö11: Indirgenmedir. Aldehit indirgenir.

A: Aldehit olduğunu nasıl anladın?

Ö11: Aldehitlerde karbonla oksijen arasında ikili bağ var. Oradan anlayabiliriz.

A: Karbonla oksijen arasındaki bu băg sadece aldehitlerde mi var?

Ö11: Ben başka molekül hatırlayamadım.

A: Reaksiyona geri dönecek olursak, bu molekülü nasıl adlandırabilirsin? Açıklar mısın?

Ö11: 2-bütenaldir. İkili bă̆ın yerini söyledim. Sonra da aldehit diye-al ekini getirdim.

A: Reaksiyon sonucu hangi ürünler oluşur?

Ö11: Primer alkol oluşur. Bütanoldür.

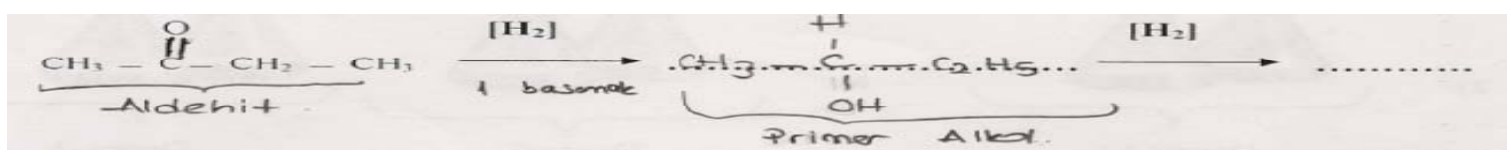

Bir başka öğretmen adayına ait alıntılar ise şöyledir:

A: Reaksiyonu hangi tür reaksiyona örnek verilebilir? Bu reaksiyonda hangi ürün ya da ürünler oluşabilir?

Ö9: Reaksiyonun adını tam olarak bilmiyorum. Ama alkan eldesi diyebilirim.

A: Neden alkan eldesi olarak tanımladın? Açıklar mısın?

Ö9: Çünkü hidrojen atomları oksijenle bağ yapan karbon atomuna bağlandl. Yani oradaki ikili bă̆ koptu ve su açı̆̆a çıktı. Böylece alkan oluştu.

A: Oluşan alkanı adlandırabilir misin?

Ö9: Bütan. 


\section{Sonuç ve Tartışma}

Fen bilgisi öğretmen adaylarının, alkoller konusunun temel kavram ve reaksiyonlarına ilişkin anlama düzeylerinin ve kavram yanılgılarının araştırıldığı bu çalışmada, önemli bulgular elde edilmiştir. Araştırma sonucunda, kavram testindeki alkollerin sınıflandırılması ve kaynama noktası ile ilgili olan 1. ve 7. sorular hariç, geriye kalan 14 soruda öğretmen adaylarının yarıdan daha az bir kısmı tam anlama kategorisine giren cevapları verebilmişlerdir. Aynı zamanda, öğretmen adayları ile yapılan görüşmelerde de kavram testindeki bulguları destekleyen sonuçlar ortaya çıkmıştır. Özellikle, kavram testindeki sorular tek tek ele alındığında öğretmen adaylarının "alkol olma koşulları, alkollerin genel özellikleri, sudaki çözünürlükleri, yapı izomerisi, adlandırılması, yükseltgenmesi, sodyum ile reaksiyonlar, Lucas ayıracı ile tepkimeleri, dehidrasyon tepkimeleri, alkil halojenürlerden ve indirgenme reaksiyonlarından alkol eldesi" konu başlıklarında tam anlama düzeylerinin yeterli olmadığı ve kavram yanılgılarının \%48 gibi yüksek oranlara çıktığı saptanmıştır.

Bu konulardan alkol olma şartı ile ilgili hem kavram testinde hem de görüşmede bir soru yer almıştır. Kavram testinde saptanan kavram yanılgılarından, "bir molekülün alkol olması için molekülde $\pi$ bă̆ olmamalıdır ve halkalı yapılar, alkol özelliği taşımaz”, yanılgılarına literatürde rastlanmazken, "bir molekülün alkol olması için hidroksil grubu (-OH) taşıması yeterlidir” yanılgısı ise Potgietera ve Davidowitz (2011) tarafından yürütülen araştırmada da ortaya çıkmıştır. Görüşmeden elde edilen bulgularda ise, öğretmen adaylarının \%42 gibi yüksek bir oranda alkol olma koşullarının bir kısmını ifade ederek kısmen anlama kategorisinde yer aldıkları saptanmıştır. Bu sonuç, özellikle öğretmen adaylarının bir molekülün alkol olup olmadığı belirlerken öncelikle hidroksil grubuna odaklandıklarını, hidroksil grubunun bağlı olduğu karbon atomunun hibrit türüne ve bu karbon atomuna kaç hidroksil grubunun bağlandığına çok dikkat etmediklerini göstermektedir.

Araştırmada saptanan önemli bulguların bir bölümü ise alkollerin fiziksel özellikleri olan çözünürlükleri ve kaynama noktaları ile ilgilidir. Alkollerin sudaki çözünürlüğü ile ilgili olarak saptanan "C sayısının artması alkollerin sudaki çözünürlüğ̈̈nü artırır, dallanmanın artması alkollerin sudaki çözünürlüğ̈̈nü azaltır” kavram yanılg1sı öğretmen adaylarının kaynama noktasına etki eden faktörleri çözünürlüğe de uygulamalarından kaynaklanabilir. Aynı zamanda, öğretmen adaylarında "aynı karbon sayılı düz ve dallanmış alkollerin sudaki çözünürlükleri aynıdır" yanılgısı da belirlenmiştir. Bu yanılgılar, literatürde rastlanmayan yanılgılardandır. Alkollerin kaynama noktası ile ilgili olarak ise, görüşmede daha detaylı sonuçlar elde edilmiştir. Özellikle, öğretmen adayları verilen molekülleri kaynama noktalarına 
göre karşılaştırırken, molekül içindeki oksijen ile hidrojen atomları arasındaki bağı hidrojen bağı olarak kabul etmekte ve hidrojen bağının elektron ortaklığ1 sonucu oluştuğuna inanmaktadırlar. Bu yanılgı, Ünal, Çostu ve Ayas (2010)'ın bulgularıyla da uyuşmaktadır. Görüşmede elde edilen önemli bulgulardan biri de etil alkol ile dimetil eteri birbirinden ayırt etmede kullanılan kaynama noktası farkının bir kimyasal reaksiyon olarak görülmesidir. Öğretmen adayı 10 (Ö10)'nun açıklamalarından daha net bir şekilde anlaşılacağı üzere, sıvıların kaynama sürecinde 1sitılması kimyasal bir olay olarak nitelendirilmiştir. Benzer bulgulara literatürdeki çeşitli çalışmalarda da rastlanmıştır (Demircioğlu, Demircioğlu, Ayas \& Kongur, 2012; Sökmen, Bayram \& Gürdal, 2000). Bu durum, kimyasal değişimin basit yöntemlerle geri dönüştürülemeyen bir değişme olarak tanımlaması ve öğretmen adayının gaz halindeki dimetil eter ve etil alkolünde tekrar sıvı hale gelebileceğine inanmamasından kaynaklanabilir.

Kavram testinden elde edilen bulgular, öğretmen adaylarının alkollerin genel özellikleri ve yapı izomerisi konularında da kavram yanılgılarının olduğunu göstermektedir. Bu kavram yanılgılarından, “tüm mono alkoller $\mathrm{C}_{n} \mathrm{H}_{2 n+2} \mathrm{O}$ kapalı formülü ile gösterilir” ve "bütün alkollerin eter izomerisi vardır" yanılgıları öğretmen adaylarında yüksek oranlarda mevcut olup, literatürde karşılaşılmayan kavram yanılgılarındandır. Yapı izomerisi ile ilgili olarak da "bütün alkollerin eter izomerisi vardı", "sadece dioller ve trioller eter ile izomerdir" yanılgıları öğretmen adaylarının eterlerin sembolik gösteriminde zorlanmalarından ya da yapı izomerisini tam kavramamasından kaynaklanabilir. Nitekim, çeşitli araştırmalarda da izomeri kavramında, öğrencilerin kavramsal algılamalarının yeterli olmadığı belirtilmiştir (Moss, Greenall, Rockcliffe, Crowley\& Mealing, 2007; Schmidt, 1992; Şendur, 2012).

Aynı zamanda, öğretmen adaylarının alkollerin adlandırmasında da kavram yanılgılarının olduğu ortaya çıkmıştır. Burada dikkat çekici olan, öğretmen adaylarının alkol molekülünü adlandırırken, hidroksil grubuna değil de $\mathrm{C}=\mathrm{C}$ bağına öncelik vererek molekülü adlandırmalarıdır. $\mathrm{Bu}$ durum, öğretmen adaylarının alken adlandırmasındaki $\mathrm{C}=\mathrm{C}$ bağına verilen öncelik durumunu genellemelerinden kaynaklanabilir.

Araştırmada, hem kavram testi hem de görüşmeden elde edilen bulgularda pek çok öğretmen adayının alkollerin kimyasal tepkimelerinin sembolik gösterimlerinde yeterli düzeyde olmadıkları ve aldehit, keton, karboksilli asit gibi fonksiyonel gruplu bileşikleri tam olarak kavrayamadıkları belirlenmiştir. Ramnarain ve Joseph (2012) tarafından yürütülen bir araştırmanın bulguları da, öğrencilerin organik tepkimelerin mikroskobik ve sembolik gösterimlerine ilişkin anlama düzeylerinin yeterli olmadığını ortaya koymaktadır. Bunlara 
ilaveten, öğretmen adayların önemli bir kısmı, alkollerin tepkimelere olan yatkınlıklarının ya da tepkime hızının primerden, sekonder ve tersiyer alkole doğru azaldığını düşünmektedir. Örneğin, "metalik sodyumla sadece primer alkoller tepkime verir" yanılgısının öğretmen adaylarındaki oranı, aynı tepkimeyi sekonder alkol ve tersiyer alkol verir diyenlerden çok daha yüksektir. Benzer bir şekilde, "Lucas ayıracı ile en hızlı tepkimeyi primer alkoller verir" yanılgıs1, "Lucas ayıracı ile en hızlı tepkimeyi sekonder alkoller verir" yanılgısından daha yüksek oranda olup, bu kavram yanılgılarına literatürde karşılaşılmamıştır. Bu duruma, primer, sekonder ve tersiyerin kelime anlamının birincil, ikincil ve üçüncül olması etkili olmuş olabilir. Araştırma bulguları, öğretmen adaylarının yükseltgenme reaksiyonları ile ilgili olarak da yeterli anlama düzeylerinin olmadığını ve kavram yanılgılarının yoğunlaştığını göstermektedir. $\mathrm{Bu}$ yanılgılardan "sikloheksanol halkalı yapıda bir alkol olduğu için yükseltgenmez" yanılgısı kavram testinde belirlenirken, "benzil alkol halkalı yapıda olduğu için yükseltgenemez" yanılgısı da görüşmede ortaya çıkmıştır. Bu sonuç, öğretmen adaylarının daha çok düz yapılı alkol örnekleri ile karşılaşmalarından kaynaklanabilir. Nitekim öğretmen adayı 11(Ö11)'in görüşmede yapı̆̆ı açıklamalar da bu sonucu desteklemektedir. Öğretmen adaylarının bu sorulara verdikleri cevaplarda aynı zamanda primer, sekonder, tersiyer alkolü ve bunların yükseltgenmesi ile oluşacak ürünleri de tam olarak kavrayamadıkları belirlenmiştir. Örneğin, kavram testinde belirlenen "tersiyer alkol yükseltgenmesi ile keton oluşur" ve "sekonder alkol yükseltgenmez" kavram yanılgılarından bu durum daha net bir şekilde ortaya çıkmaktadır. Öğretmen adaylarının, alkollerin kimyasal tepkimelerinden biri olan dehidrasyon tepkimesine ilişkin de tam anlama düzeyleri yeterli düzeyde olmayıp, kavram yanılg1ları mevcuttur. Bu yanılgılardan, "etil alkolün 2 molünden, $140{ }^{\circ} \mathrm{C}$ de $\mathrm{H}_{2} \mathrm{SO}_{4}$ varlı̆̆ında 1 mol su çekilmesiyle ana ürün olarak bir mol ya da 2 mol eten elde edilir" yanılgıları bu öğretmen adaylarının tepkimenin gerçekleştiği koşulları dikkate almadığını, benzer tepkimelerin farklı koşullarda gerçekleştiğinde eter ya da alkenin ana ürün olabileceğini tam olarak kavrayamadıklarını göstermektedir.

Öğretmen adaylarında saptanan kavram yanılgılarının bir bölümü de alkollerin eldesi ile ilgilidir. Özellikle, “alkil halojenürlerin seyreltik kuvvetli bazlara ısıtılmasında ana ürün alken olur" kavram yanılgısı öğretmen adaylarının alkil halojenürlerin nükleofilik yer değiştirme reaksiyonunu eliminasyon reaksiyonu olarak uyguladıklarını göstermektedir. Bir diğer kavram yanılgısı olan "alkil halojenürlerin seyreltik kuvvetli bazlara ısitılmasında ana ürün alkin olur" yanılgısı ise öğretmen adaylarının alkinlerin, alkil dihalojenürlerden elde edilebileceği bilgisini yanlış uyguladıklarını ortaya çıkarmaktadır. Literatürdeki çeşitli 
araştırmalarda da öğrencilerin reaksiyon türüne, mekanizmasına dikkat etmeden reaksiyonda oluşan ürünü yazdıkları saptanmıştır (Bhattacharyya \& Bodner, 2005; Rushton, Hardy, Gwaltney \& Lewis, 2008; Şendur, 2012).

Aynıca, alkollerin diğer bir elde yöntemi olan indirgenme reaksiyonlarında da önemli bulgular ortaya çıkmıştır. Bu bulgular özellikle, yükseltgenme reaksiyonlarında elde edilen bulguları destekler biçimdedir. Örneğin, öğretmen adaylarının sinin "ketonların indirgenmesi ile tersiyer alkoller oluşur" yanılgısı, "tersiyer alkol bir basamak yükseltgenir ve keton oluşur" yanılgısı ile aynı sonucu ortaya koymaktadır. Bunların yanında "ketonların indirgenmesi ile primer alkol oluşur", "ketonlar indirgenmez" yanılgıları da kavram testinde saptanan ve literatürdeki çalışmalarda karşılaşılmayan kavram yanılgılarındandır. Görüşme sonuçlarında ise dikkat çekici olan, öğretmen adaylarının keton molekülünü aldehit olarak kabul etmeleri ve oluşan sekonder alkolü de primer alkol olarak sınıflandırmalarıdır. Benzer şekilde Hassan, Hill ve Reid (2004) tarafından yürütülen araştırmada da, öğrencilerin alkolleri sınıflandırmada bazı problemler yaşadıkları ortaya çıkmıştır. Alkollerin eldesi ile ilgili olarak, öğretmen adaylarının kavram testinde en düşük tam anlama yüzdesine sahip oldukları soru karboksilli asitlerin indirgenmesi ile ilgili olan 16. soruda olmuştur. Bu soruda özellikle öğretmen adaylarının pentanoik asidin yapı formülünü yazarak, indirgenme ürünlerini yazmada zorlandıkları anlaşılmaktadır. Ayrıca soruda saptanan "karboksilli asitlerin iki basamak indirgenmesi ile sekonder alkol","tersiyer alkol” ve "eterler oluşur" şeklindeki kavram yanılgıları öğretmen adaylarının ketonlarda olduğu gibi karboksilli asitlerin indirgenme reaksiyonunu da tam olarak uygulayamadıkları göstermektedir.

Sonuç olarak, fen bilgisi öğretmen adaylarının alkoller konusunun temel kavram ve reaksiyonlarında ilişkin yeterli kavramalara sahip olmadıkları hatta bunlarla ilgili önemli kavram yanılgılarına sahip oldukları sonucuna ulaşılmıştır.

\section{Öneriler}

Yapılan bu araştırma sadece fen bilgisi öğretmen adayları ile sınırlıdır. Organik kimya ile ilgili yürütülen araştırmaların son derece sınırlı olduğu düşünülürse, benzer araştırmalar ortaöğretim öğrencileri ya da kimya öğretmen adayları üzerinde daha geniş örneklemler de yürütülerek, benzer kavram yanılgılarına sahip olup olmadıkları araştırılabilir. Bu bağlamda, bir sonraki aşama bu kavram yanılgılarını giderici yöntemlerin uygulanması, olumlu bir yönde kavramsal değişimin olup olmadığının araştırılması olabilir. Özellikle, alkol türlerinin ve fonksiyonel gruplu diğer organik bileşiklerin öğrencilerin zihinlerinde daha iyi 
yapılandırılması için molekül modelleri ya da bilgisayar animasyonlarından öğretim sırasında yararlanılabilir. Araştırmada, çıkan önemli bir sonuç, pek çok öğretmen adayının kimyasal tepkimelerin sembolik gösteriminde zorlandıkları ve bu tepkimeleri karıştırdıklarıdır. $\mathrm{Bu}$ durumun giderilmesi için tepkimelerin özelliklerini ve birbirleriyle ilişkilerini yapılandırmalarını sağlayan kavram haritaları ya da yapılandırılmış gridler hazırlanarak öğretim sırasında kullanılacak materyallere entegre edilebilir.

\section{Kaynakça}

Abraham, M. R., Grzybowski, E. B., Renner, J. W. \& Marek, E. A. (1992). Understandings and misunderstandings of eight grades of five chemistry concepts found in textbooks. Journal of Research in Science Teaching, 29 (2), 105-120.

Asker, E., Genç, H., Meriç, G., Saraçoğlu, M., Sürücü, A., Topal, G., Toy, M. \& Y1lmaz, H. (2007). Genel kimya 4 organik kimya. (Edt. Giray Topal, Hüseyin Bağ). Ankara, Pegem A Yayıncilik.

Ayas, A. \& Demirbaş, A. (1997). Turkish Secondary Students' Conception of Introductory Chemistry Concepts. Journal of Chemical Education, 74(5), 518-521.

Atkins, R. C. \& Carey, F. A. (2009). Organik kimya klsa ve öz. (Çev. Edt. Gürol Okay, Y1lmaz Y1ldırır). Ankara, Bilim Yayınevi.

Azizoğlu, N., Alkan, M. \& Geban, Ö. (2006). Undergraduate pre-service teachers' understandings and misconceptions of phase equilibrium. Journal of Chemical Education, 83, 947-953.

Bhattacharyya, G. \& Bodner, G. M. (2005). It gets me to the product: how students propose organic mechanisms. Journal of Chemical Education, 82, 1402-1407.

Büyüköztürk, Ş., Kılıç Çakmak, E., Akgün, Ö.E., Karadeniz, Ş., \& Demirel, F. (2008). Bilimsel Araştırma Yöntemleri. Ankara: Pegem Yayınları

Chiu, M.H. (2007). A national survey of students' conceptions of chemistry in Taiwan. International Journal of Science Education, 29(4), 421-452.

Coştu, B., Ayas, A. \& Niaz, M. (2009). Promoting conceptual change in first year students' understanding of evaporation. Chemistry Education Research and Practice, 11, 5-16.

Çalık, M. (2005). A cross-age study of different perspectives in solution chemistry from junior to senior high school. International Journal of Science and Mathematics Education, 3, 671-696. 
Çalık, M., Ayas, A. \& Ünal, S. (2006). Çözünme kavramıyla ilgili öğrenci kavramalarının tespiti: bir yaşlar arası karşılaştırma çalışması. Gazi Üniversitesi Türk Eğitim Bilimleri Dergisi, 4(3), 309-322.

Çepni, S. (2007). Araştırma ve Proje Çalışmalarına Giriş. (Genişletilmiş Üçüncü Baskı). Trabzon, Celepler Matbaacılık.

Demircioğlu, H., Demircioğlu,G., Ayas, A. \& Kongur, S. (2012). Onuncu sınıf öğrencilerinin fiziksel ve kimyasal değişme kavramları ile ilgili teorik ve uygulama bilgilerinin karşılaştırılması. Türk Fen Ĕ̈itimi Dergisi, 9 (1), 162-181.

Ebel,R.L. \& Frisbie, D.A. (1991). Essentials of Educational Measurement. (Fifth Edition). Englewood Cliffs, New Jersey: Prentice Hall.

Gabel, D.L., Samuel, K.V. \& Hunn, D. (1987). Understanding the particulate nature of matter. Journal of Chemical Education, 64(8), 695-697.

Hart, H., Hart, D. J. \& Craine, L. E. (2005). Organik kimya. (Çev. Edt. Tahsin Uyar). Ankara, Palme Yayıncılık.

Haslam, F. \& Treagust, D. F. (1987). Diagnosing secondary students' misconceptions of photosynthesis and respiration in plants using a two-tier multiple choice instrument. Journal of Biological Education, 21(3), 203-211.

Hassan, A.K., Hill , R. A. \& Reid, N. (2004). Ideas underpinning success in an introductory course in organic chemistry. University Chemistry Education, 8, 40-51.

Hewson, P. W. \& Hewson, M. G. (1984). The role of the conceptual conflict in conceptual change and the design of science instruction. Instructional Science, 13, 1-13.

Hinton, M.E. \& Nakhleh, M.B. (1999). Students' microscopic, macroscopic, and symbolic representations of chemical reactions. Chemical Educator, 4, 158-167.

Johnstone, A.H. (1982). Macro- and micro- chemistry. School Science Review, 64, 377-379.

Johnstone, A. H. (1991). Why is science difficult to learn? Things are seldom what they seem. Journal of Computer Assisted Learning, 7, 75-83.

Karaer, H. (2007). Alkollerin suda çözünmelerini açıklayan bir dramatizasyon etkinliğinin geliştirilmesi ve uygulanması. Ondokuz Mayıs Üniversitesi Eğitim Fakültesi Dergisi, $24,25-32$.

Miles, M. B. \& Huberman, A. M. (1994). An expanded sourcebook qualitative data analysis. United States of America, Sage Publications.

Moss, K., Greenall, C., Rockcliffe, A., Crowley, M. \& Mealing, A. (2007). Threshold 
concepts, misconceptions and common issues. Proceedings of the Science Learning and Teaching Conference 2007 (pp. 190-196), England: Keele University.

Nakhleh, M.B. (1992). Why Some Students Don't Learn Chemistry. Journal of Chemical Education, 69(3), 191-196.

Özdamar, K. (2004). Paket Programlar ile İstatistiksel Veri Analizi 2. Eskişehir: Kaan Kitabevi.

Özmen, H. (2007). The effectiveness of conceptual change texts in remediating high school students' alternative conceptions concerning chemical equilibrium. Asia Pacific Education Review, 8 (3), 413-425.

Patton, M.Q. (1987). How to use qualitative methods in evaluation. Newbury Park, CA: Sage Potgietera, M. \& Davidowitz, B. (2011). Preparedness for tertiary chemistry: multiple applications of the chemistry competence test for diagnostic and prediction purposes. Chemistry Education Research and Practice, 12, 193-204.

Ramnarain, U. \& Joseph, A. (2012). Learning difficulties experienced by grade 12 South African students in the chemical representation of phenomena. Chemistry Education Research and Practice, 13, 462-470.

Raviola, A. (2001). Assessing students' conceptual understanding of solubility equilibrium. Journal of Chemical Education, 78(5), 629-631.

Ross, B. \& Munby, H. (1991). Concept mapping and misconceptions: A study of high school students' understandings of acids and bases. International Journal of Science Education, 13, 11-23.

Rushton, G.T., Hardy, R.C., Gwaltney, K.P. \& Lewis, S.E. (2008). Alternative conceptions of organic chemistry topics among fourth year chemistry students. Chemistry Education Research and Practice, 9,122-130.

Sax, G. (1997). Principles of Educational and Psychological Measurement and Evaluation. (Fourth Edition). Belmont, CA: Wadsworth.

Schmidt, H.J. (1992) Conceptual difficulties with isomerism. Journal of Research in Science Teaching, 29, 995-1003.

Solomons, G. \& Craig, F.(2002). Organik kimya. (Çev. Edt. Gürol Okay, Yılmaz Yıldırır). İstanbul, Literatür Yayıncılık.

Suen, H.K. (1990). Principles of test theories. L. Erlbaum Associates, Hillsdale, NJ. 
Sökmen, N., Bayram, H. \& Y1lmaz, A. (2000). 5., 8. ve 9. sınıf öğrencilerinin fiziksel değişim ve kimyasal değişim kavramlarını anlama seviyeleri. M.Ü. Atatürk Eğitim Fakültesi Ĕ̈itim Bilimleri Dergisi, 12, 261-266.

Şencan, H. (2005). Sosyal ve davranışsal ölçümlerde güvenilirlik ve geçerlilik. Ankara, Seckin Yayınc1lik.

Şendur, G. (2012). Fen bilgisi öğretmen adaylarının organik kimyadaki kavram yanılgıları: alkenler örneği. Türk Fen Eğitimi Dergisi, 9 (3), 160-185.

Toprak, M., Alp, S. \& Karagöz, M.(2001). Organik kimya temel terimler, temel tanımlar. İzmir, Dokuz Eylül Üniversitesi Matbaası.

Ünal, S., Coştu, B. \& Ayas, A. (2010). Secondary School Students' Misconceptions of Covalent Bonding. Journal of Turkish Science Education, 7( 2), 3-29.

Yıldırım, A. \& Şimşek, H. (2011). Sosyal bilimlerde nitel araştırma yöntemleri. Ankara, Seçkin Yayıncılık.

Yin, R. K. (1984). Case study research: design and methods. Beverly Hills, CA, Sage. 